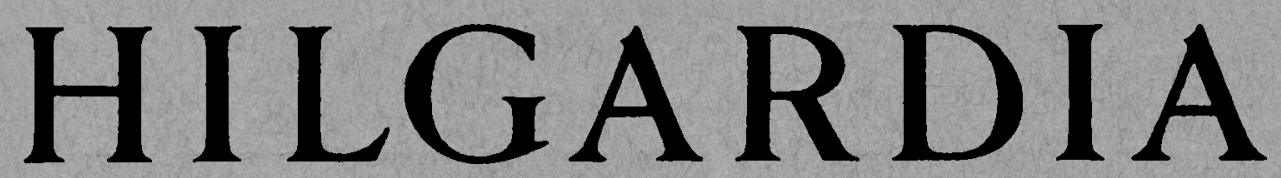

A Journal of Agricultural Science Publisbed by the California Agricultural Experiment Station

\title{
FUNDAMENTALS OF BIOLOGICAL CONTROL OF WEEDS
}

\author{
C. B. HUFFAKER
}




\section{CONTENTS}

Introduction . . . . . . . . . . . . . . . . . . . . . 101

The nature of weed infestations and the place of biological control . . . 102

The losses due to weeds . . . . . . . . . . . . . . . 103

Conflicting interests and the lack of control over introduced species . . 103

The noxious nature of the weed and the prospects of successful control . . . . . . . . . . . . . . . 106

The kinds of natural enemies . . . . . . . . . . . . . . 108

The nature of damage to the weed . . . . . . . . . . . . . . . 111

Direct and indirect destruction . . . . . . . . . . . . . . 111

The plant parts attacked . . . . . . . . . . . . . 112

The subtlety of action . . . . . . . . . . . . . . . . . 113

Numbers of insects required to destroy a plant . . . . . . . . . 113

The risks of introduction and host specificity . . . . . . . . . 115

Acceptability of hosts and restrictions of diet . . . . . . . . . 116

Records of "Changes in Diet" . . . . . . . . . . . . . 117

The relative safety of different types of feeding . . . . . . . . 119

Other factors offecting specificity . . . . . . . . . . . . . 120

The balance in nature . . . . . . . . . . . . . . 120

Changes in abundance . . . . . . . . . . . . . . . . 121

The premise of reëstablishing balance by introduction of natural enemies . . . . . . . . . . . . . . . . . . 124

Plant food as limiting insect numbers . . . . . . . . . . . 125

The role of insects in plant ecology . . . . . . . . . . . . . 129

Environmental fitness and the choice of agents . . . . . . . . . 135

The aggressiveness of weeds in invaded regions . . . . . . . . 135

The relation of climate to the choice of agents . . . . . . . . . 138

The pyramid of adaptations and exploitation . . . . . . . . . 139

Procedures . . . . . . . . . . . . . . . . . 140

Foreign exploration for natural enemies . . . . . . . . . . 141

"Starvation Tests" on specificity . . . . . . . . . . . . . . 141

Quarantine considerations . . . . . . . . . . . . 143

Culture and colonization . . . . . . . . . . . . . . . . 144

Evaluation of results . . . . . . . . . . . . . . . 146

Summary . . . . . . . . . . . . . . . . . . 148

Acknowledgments . . . . . . . . . . . . . . . . . 150

Literature cited . . . . . . . . . . . . . . . . . . 150 


\section{H I L G A R D I A}

A Journal of Agricultural Science Published by

the California Agricultural Experiment Station

VoL. 27

SEPTEMBER, 1957

No. 3

\section{FUNDAMENTALS OF BIOLOGICAL CONTROL OF WEEDS ${ }^{1}$}

\section{B. HUFFAKER ${ }^{2}$}

\section{Preface}

The critical phase of biological control work against weeds is the selection of species that will not harm other plants, or at least useful plants. All other considerations are subordinate, and a suitable species for introduction into a country against a weed is one that is safe to introduce, irrespective of its other characteristics.-J. R. Williams $(1954)^{3}$

\section{INTRODUCTION}

SINCE THE beginning of agriculture man has engaged in a never-ending struggle to rid his lands of weeds. In this age of chemistry, there are yet millions of acres of land on which weeds flourish and where they either do not yield to chemicals used against them, or else this solution has proved impracticable for other reasons. With some of the worst weeds known where chemical, mechanical, or precautionary measures have failed, biological control, or the employment of natural enemies, has proved eminently successful.

The objective in this work is not eradication, but the reduction of weed densities to levels largely noninjurious to man's interests. In this field where host-specific agents must be employed, eradication is inconceivable over any appreciable natural area. As will be shown later, control may be accomplished either by direct action of the introduced agents or through other actions set in motion by such agents. The fauna and flora of infested lands constitute an ecological entity which may represent either a barrier or an open highway to success.

Employment of biological methods of weed control has been hesitantly approached for two reasons: 1) fear that the risks involved are too great as compared with the chances of success, and 2) the conflict in general acceptance of a given plant as a weed, coupled with the fact that introduced natural enemies of weeds would be free to move into other lands where the plant may be considered of value. The first and most important reason for hesitancy is losing its force because of accumulating evidence of successes and greater assurances against disproportionate risk.

\footnotetext{
${ }^{1}$ Received for publication February 11, 1957.

${ }^{2}$ Entomologist in Biological Control in the Experiment Station, Berkeley.

${ }^{3}$ See "Literature Cited" for citations, referred to in the text by author and date.
} 
The close relation of biological control of insect pests and of weeds is apparent. Obvious also is the ecological foundation upon which both of these sciences rest. Mutual benefit has derived from the researches in these kindred fields. Thus, practical entomologists, looking at their problems of insect pests as ecologists, have made noteworthy contributions to the advance of our concepts of population phenomena in general. To mention only a few, the works of Howard and Fiske (1911), Chapman (1931, 1933), Uvarov (1931), Nicholson (1933, 1954), Smith (1935), Thompson (1939), and Solomon (1949) are noteworthy examples which have advanced our understanding of the physical and the biotic components of environments. Just as these workers have profited by and helped to advance animal ecology, practical entomologists, or weed-control specialists, in their attempts to control weeds biologically, also have much to gain and much to offer by approaching their problems as ecologists. In this field plant ecology rises to full parity.

Tillyard (1929a) and Sweetman (1936) referred to the inverse aspect of the problems of biological control of weeds and of insect pests. This view may have drawn attention away from the more fundamental and more general similarities. The two fields are inverse only in the sense that in the biological control of weeds, plants are the pests to be destroyed; whereas attempts to control most insects by this means are for the protection of plants. However, insects have been the principal agents employed in each field. Of course, interests in the two fields would exist at cross purposes under conceivable circumstances whereby parasites and predators introduced to attack insect pests would also significantly attack related phytophagous forms introduced for the control of a weed. An example of such is reported by Dodd (1953).

Many of the principles and procedures of biological control as applied to insect pests pertain also in the control of weeds. No attempt will be made to cover these principles in this paper, but such questions are considered as are peculiar to, or need particular emphasis in, attempts to control weeds by this means. A limited amount of the material included has been stated previously, particularly by Imms (1926, 1929, 1937), Tillyard (1929a, 1929b), Sweetman (1936), Wilson (1943, 1949, 1950, 1953, 1954), Williams (1954), Dodd (1940, 1954), Holloway (1954), and others in various short accounts of the general subject. However, the past ten years have been very active ones. Some of the views and concepts previously expressed need revision, and there is need for a more comprehensive treatment of fundamentals.

No attempt is made to review the currently active programs throughout the world. These will be referred to only as they exemplify some principle or pertinent point, with obvious particular attention being given to the examples in the United States in which work the author has been engaged.

\section{THE NATURE OF WEED INFESTATIONS AND THE PLACE OF BIOLOGICAL CONTROL}

Each weed coming under consideration as a subject for biological control must be viewed from many aspects, for this method of control is applicable only if the proper relations pertain. 


\section{The Losses Due to Weeds}

A weed is a plant in the wrong place. There is no other feature common to and peculiar to all weeds. They may be closely related to, or may themselves be, valuable plants in other situations. A clear understanding of this fact is fundamental to a proper evaluation of the possibilities and consequences of attempts at biological control. It is for this reason that each specific weed problem must be considered from many points of view.

Entomologists may be surprised to learn that agriculturists have sometimes rated weeds as several times more destructive to agriculture than are insects (Robbins et al., 1942, p. 12). A list of the types of losses due to weeds will illustrate the scope of ecological relations and of man's varied interests important in considering weed subjects for biological control:

1. Competitive crowding out or reducing the growth of desirable plants, causing losses in yield, quality, and unit value, in spite of costly precautionary and direct control measures.

2. Much of the cost of cultivation.

3 . The need for special seed and grain cleaning.

4. Direct injury to man, livestock, or livestock products.

5. Depreciation of watershed and wildlife values.

6 . Weeds may serve as essential alternate hosts for insect pests or plant pathogens.

\section{Conflicting Interests and the Lack of Control Over Introduced Species}

Evaluating the Economic Position of the Weed. With other methods of weed control it is not so necessary to establish the over-all net economic worth or debit value for a plant known to be noxious in a given area or detrimental to a specific interest. Physical, chemical, or cultural methods of control can in general be limited to the terrain desired to be cleared of a given plant. An exception would be the use of presumed-to-be-desirable plant competitors. Such plants can spread to other areas and become serious weeds and these fall in a category with the introduced phytophagous insects or other organisms which on their own may broaden their scope of activity beyond that intended.

A plant may be a pest in one area and useful in another, or it may be harmful to one interest and beneficial to another in the same area. As Wilson (1949) stated, "... a weed may be equivocally noxious."

With biological control, therefore, an accurate appraisal of the net economic position of the weed subject over the entire land mass where it is found is mandatory. The broadest possible viewpoint must be maintained. There must be considered the probability of future values as well as present ones (Miller, 1936) ; minority as well as majority rights ; interests of neighboring nations on the same or accessible land mass; direct or indirect effects upon other plant or animal species and upon the soil itself. Yet, formulas for considerations should be elastic (Dodd, 1954).

As a general example, there are situations wherein a rather objectionable 
plant in other respects may occupy extensive lands which would in the long view be seriously damaged rather than improved by the removal of such a "weed." This is particularly true in cases where the plant fills a niche which, in its absence, would not readily be filled by other more desirable species in relatively barren environments which for climatic or edaphic reasons do not sustain a wide variety of well-adapted and ecologically overlapping species that would quickly claim the space vacated by the weedy subject. In some such cases serious soil erosion by wind or water, a disturbance of the normal seral stages in succession to climax vegetation, and similar influences on the fauna inhabiting such areas may constitute sufficient grounds for refusal of such a program. Only evidence presented by competent biologists familiar with the plant and animal ecology in relation to the particular environment should be valid in making predictions which would constitute grounds for refusal.

A few specific examples will illustrate the complexity:

1. Prickly Pear or Opuntia spp. Regarding control of this weed in Australia by Cactoblastis, Dodd (1940) stated, "The prickly pear territory has been transformed as though by magic from a wilderness [of 60 -million acres of infested lands] to a scene of prosperous endeavour." From Australia there seem to have been raised no dissenting voices (see figure 1). On the other hand, in Hawaii (see figure 2) there were vigorous objections against the proposed program of biological control of this plant there. Fullaway (1954) reported that cattlemen objected on the grounds that the tree cactus, Opuntia megacantha Salm-Dyck., is useful both as a feed and as a source of otherwise unavailable water on some ranges. Such a program has also been opposed in the United States largely out of deference to similar sentiments in both Mexico and this country and to considerations of the value of the plant in relation to soil and wildlife conservation.

2. Chamise, Adenostoma fasciculatum H. \& A., is considered a serious pest by some elements of the cattle industry in California, but land-use or waterresource specialists would deplore its removal.

3. Yellowstar Thistle, Centaurea solstitialis Linn., in California is a most complicated case. It involves the interests of cattlemen, beekeepers, and fruit and seed crop growers. The damage caused by the weed is to the grazing ranges and to grain and seed crops. This thistle is reported to be a key plant in the maintenance of the bee industry at a level commensurate with the requirements of bees in the pollination of the fruit and seed crops in the state. This problem has not yet been resolved.

4. A Prospect for the Indirect Biological Control of the beet leafhopper and the disease it transmits to tomatoes and other crops by introduction of insects to destroy a key plant host, Russian thistle, Salsola kali var. tenuifolia Tausch., is rendered dim by assertions of competent ecologists and ranchers that this plant often serves a very useful purpose in soil conservation and as feed for livestock.

In summary, the more simplified the human economy and ecology of an area the better are the chances of attempting biological control of a weed without operating at cross purposes with self-interest. 

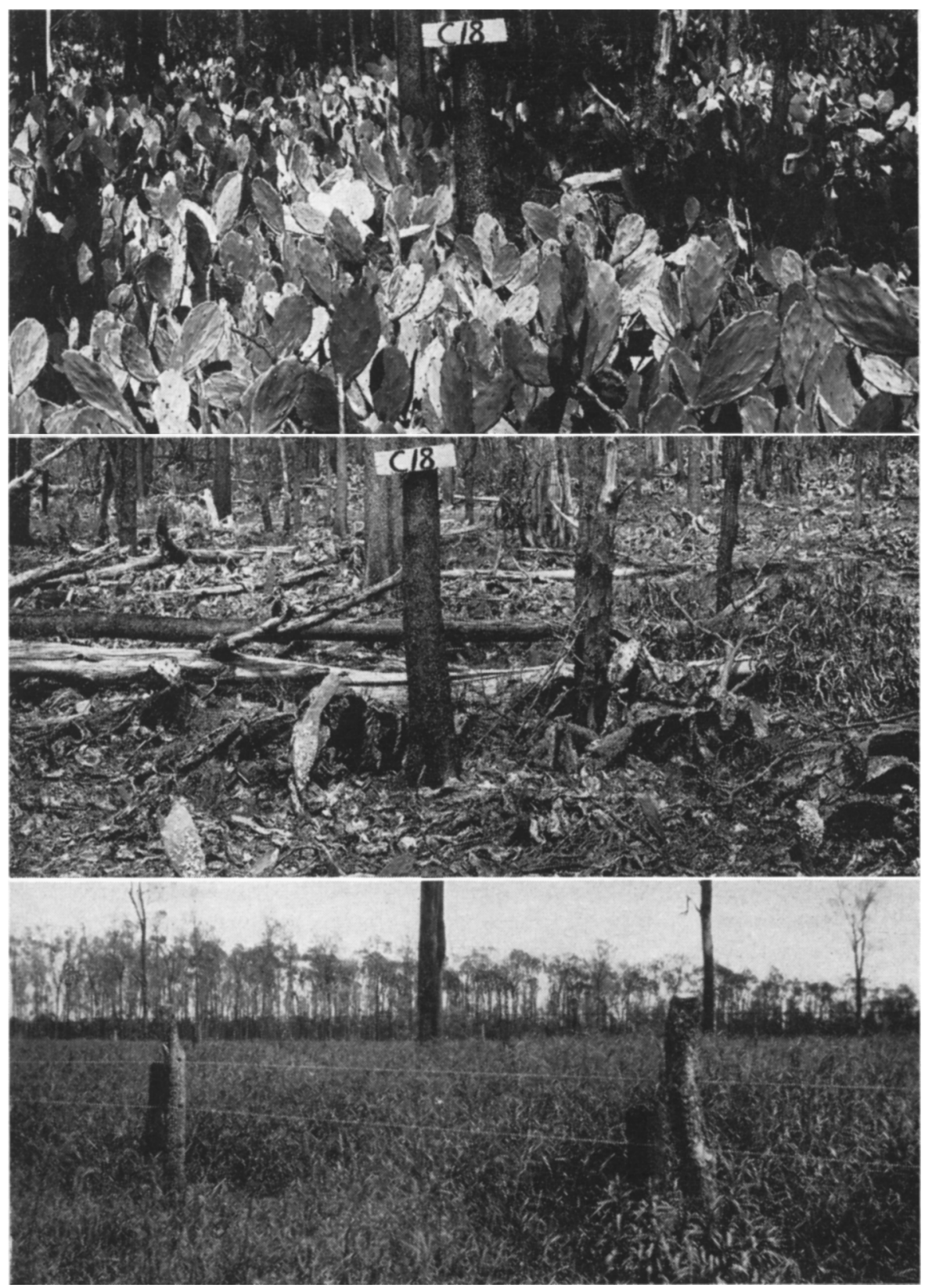

Fig. 1. Destruction by the introduced moth Cactoblastis cactorum of dense prickly pear in belar scrub country, Chinchilla, Queensland, Australia (after Dodd, 1940): Upper view, taken in October, 1926, the prickly pear in its virgin state. Middle view, three years later, in October, 1929, showing the characteristic destruction resulting from the feeding on the fleshy pads of pear by larvae of Cactoblastis. Lower view, taken in December, 1931, after trees had been cut and burnt off and the land put back into use, showing a prolific growth of Rhodesgrass. 


\section{The Noxious Nature of the Weed and the Prospects of Successful Control}

It is important whether a weed is noxious by reason of its high toxicity to animals (e.g., Halogeton glomeratus C. A. Mey. or Senecio jacobaea Linn.) because: it displaces more desirable plants or impedes their normal development; it is important as an essential alternate host of some plant pathogen or insect pest; it is detrimental mainly from its contamination of wool, for example, by its seeds (Currie, 1940) ; or is destructive to wildlife or soil conservation values. These may have a bearing upon the chances of successful control. This is also true relative to the habits of growth of the weeds.

Successful biological control depends upon the continued presence of the weed, existing in small numbers and shifting in position with time. Possibilities of biological control are remote in cases where almost complete annihilation is required, such as might occur if a weed were so highly toxic that its presence at all on a range would be ruinous to livestock; or if its noxiousness is due only to its serving as an essential alternate host of some plant pathogen which would require it at only the very lowest densities (approaching the same nonexistent status). This latter might be true if there were a very great production of inocula per plant and if the inocula were readily distributed to susceptible hosts.

An example of this [disregarding the spores which may be borne by wind currents from overwintering sources in the South] involves the common barberry, Berberis vulgaris Linn., which serves as an essential alternate host of the wheat stem rust, Puccinia graminis Pers. var. tritici, in the northern wheat regions of North America. Here the rust overwinters primarily in the teliospore stage and these spores are harmless to grains unless barberries are present nearby. Upon germination the teliospores produce sporidia which can only infect the barberries and the barberries then produce aeciospores which are carried by winds to the susceptible wheatfields. Since "as many as 70 billion aeciospores may be produced on one large barberry bush," to quote Martin and Salmon (1953), and these may be carried several miles, it is obvious that the goal in controlling barberry must be one of local annihilation.

With regard to insect pests, Carter (1935) pointed out that the degree of control necessary with an insect which is noxious by virtue of its role as a vector of a plant disease may be too strict for attainment, particularly by biological control methods.

The growth habit of a weed, its origin, and the type of land it infests are important to the chances of successful control. These points are discussed under the following topics:

1. The Economics of Control by Other Means. As Perkins and Swezey (1924), Imms (1929, 1937), Tillyard (1929b), Currie and Garthside (1932), Dodd (1940), Wilson (1943), Smith (1947), Holloway (1954), and Williams (1954) have stated or implied, the special sphere of biological control of weeds is associated with the fact that there must be relatively urgent reasons for trying the method, for responsible officials take prior recourse to other methods of control if feasible, because of the risk in introducing photophagous insects. Thus, the world's most troublesome and otherwise 
largely unsolvable weed problems have been the main objects of this method of control. Land most suitable to this approach is that which is too inaccessible or too low in value for use of chemical or other methods, or on which a weed occurs which yields to no other methods. As more is learned regarding host selection and specificity of phytophagous insects this reluctance to pursue biological control, except as a last recourse, may be gradually worn down.

2. Alien or Native Weeds. As in the case of insect pests, weeds introduced from foreign lands are the worst offenders. Examples are prickly pear, Opuntia spp., in Australia, South Africa, Asia, and Hawaii; and St. Johnswort, Hypericum perforatum Linn., in Australia, the United States, Canada, and South America. In fact, in every attempt at biological control of weeds, the subject has been an alien. Currie and Garthside (1932) and Williams (1954) considered that the theory of biological control of weeds is applicable only to alien species. In a later section of the present paper this "theory" is revised. Sweetman (1936, p. 287) stated that the control of the levuana caterpillar, Levuana irridescens Beth.-Baker, in Fiji is proof that native species of pests may be controlled by introduction of natural enemies of their near relatives.

Native weeds often have in other countries very close relatives of similar habits, synchrony of growth, and chemical and physical characteristics. It is entirely permissible - in fact, essential - to explore the prospect that there may occur in those countries insects or other natural enemies which attack those relatives and which, if introduced into the new country, would control the native noxious species. That this has not been done to any degree must surely be due to the infancy of developments in this field. An interesting example of the controlling action of a natural enemy over the destiny of a native plant is that of the removal of the native chestnut tree from the forests of eastern United States by the accidentally introduced fungus, Endothia parasitica (Murr.) And. \& And. In this case, the plant attacked is a very beneficial species, but it is seen that a native plant (or weed) may be more readily controlled than an alien form. The Asiatic chestnuts possess a high degree of resistance to this pathogen.

Two other examples similar in essentials involve the pathogenicity of the alien white-pine blister rust, Cronartium ribicola Fischer, for native white pines in North America, and the essential annihilation of Bermuda Cedars, Juniperus bermudiana Linn., on some islands of Bermuda by the accidentally introduced scale insects, Carulaspis visci (Schr.) and Lepidosaphes newsteadi Sulc. In each case the biotic agents involved appear to be much less severe in their action on their native hosts in the regions where they are endemic. The action of natural enemies in preventing this may be an important reason, but it is known that the Bermuda Cedars are highly susceptible even to fairly low densities of scale (Thompson, 1951).

Also, the classic example of control of the prickly pears, Opuntia stricta. Haw. and $O$. inermis DC. by Cactoblastis cactorum (Berg.) further illustrates this point. Although these cacti are alien to Australia, being endemic to southern North America, they do not occur in Argentina, the country from which Cactoblastis was imported to do its valuable work in Australia against these relatives of its normal hosts in its native Argentina (Dodd, 1940, p. 23). 
3. Weeds of Cultivated or Uncultivated Areas. Weeds of uncultivated areas have greatly predominated as subjects of biological control. With these examples there is less human interference which would be detrimental to the continuity of pressure and success of introduced agents. Cultivation, clean-up of refuse and the shifting aspect of the locations of weeds, along with the practices of crop rotation, use of fallow land, et cetera would have indeterminate consequences. Weeds of cultivated areas also are more readily controlled by conventional means and the economy of control by such methods is more favorable.

However, it should be noted that the propensity of insects which attack plants is such that there are often one or more species which attack a given crop species and which are sufficiently adapted and resilient in their habits as to withstand man's row-crop interferences and assume importance as major pests. Therefore, we cannot assume that weeds may not be equally likely to be attacked by certain insects in their native lands which may have equal abilities to adjust to row-crop practices and exert control over the weeds of our cultivated lands if they were introduced for that purpose. It may be expected that in such a case the fluctuations or oscillations would be of greater amplitude and time-lag in occurrence than would be the case with weeds of more natural, permanent vegetation.

4. Annual and Perennial Weeds. Even in an uncultivated area, annual weeds present the aspect of weeds of cultivated areas, but in less degree. The host stand is automatically removed at the end of each growing season. The continuity of the host-plant cover is very dependent upon the vicissitudes of ecological conditions for seed germination and establishment. Adaptations of seeds to survive for several years awaiting recurrence of favorable conditions for extensive germination assures continuity of the plant host in a dormant or inactive state. But the insects which attack them have no comparable capacities and they would not necessarily be present in adequate numbers at a trough position to respond quickly to a general increase in the abundance of their annual plant hosts and thus to check them sufficiently soon. Also, the plant pathogens, some of which possess the ability to survive for long periods in the absence of hosts, would be more adaptable, considering this aspect alone, but the conditions which favor epiphytotics are so erratic in occurrence that they would not usually be synchronized or correlated with the conditions for excessive germination of the seeds of their weed hosts.

Thus, the strictness of requirements where annual weeds are involved imposes an added impediment to success but does not preclude the possibility. Insects which have very high rates of reproduction and great powers of flight or host-finding abilities would be the best prospects for control of annual weeds. Cocklebur, Xanthium spp., is an example of an annual weed which has been a subject of this approach (Currie, 1932; Dodd, 1954), but all major successes in this field have involved perennial weeds of natural or seminatural areas.

\section{THE KINDS OF NATURAL ENEMIES}

Insects Principal Agents in Biological Control of Weeds. Beginning with the introduction of eight species of insects into Hawaii from Mexico for 

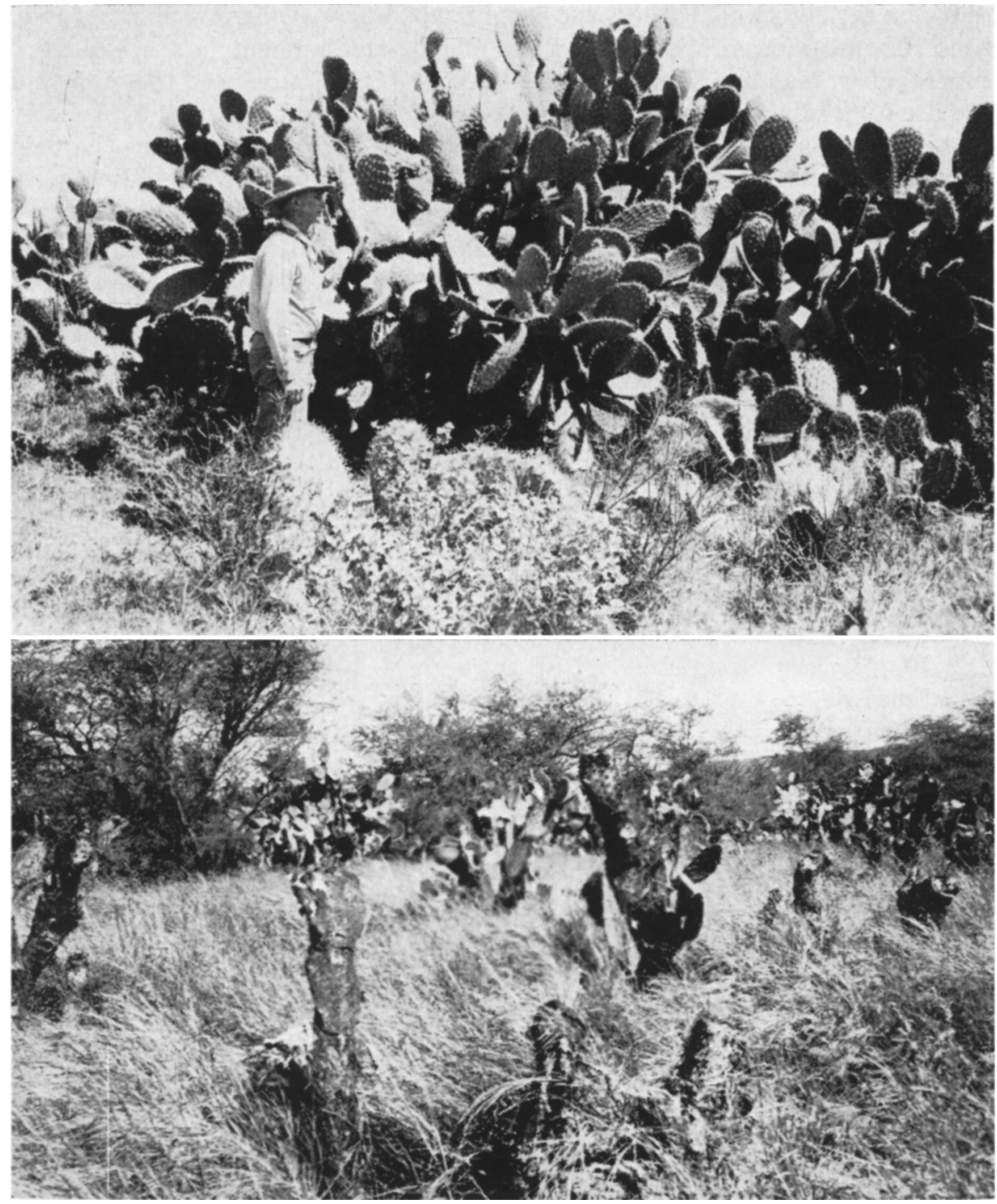

Fig. 2. In the Hawaiian Islands, Cactoblastis is given credit by H. A. Bess as the primary reason for recent destruction of large areas of tree cactus on grazing lands at low elevations. Another insect, Dactylopius opuntiae Cockerell, introduced from California, is credited with secondary importance. Upper view, typical plant undamaged by insects. Lower view, grass cover returning with the destruction of the pear by introduced insects.

control of lantana, Lantana camara Linn., at the opening of this century (Perkins and Swezey, 1924), insects have been the principal agents used in the biological control of weeds. The number of instances employing insects are many and the more important of these are listed under the subsection, "Evidence from Practical Examples of Biological Control," of the section on "The Role of Insects in Plant Ecology." 
Other Animals and Pathogenic Organisms. Parasitic higher plants, fungi, bacteria, and viruses are potential agents for employment in the biological control of weeds. Also, Piemeisel and Carsner (1951) advanced the view that the use of "replacement control" in suppression of weedy species is properly within the sphere of biological control. At some time in the future the field may well be broadened to such an extent. By controlling or withholding grazing by sheep and cattle they were able to produce a marked change in the vegetation; passing through several seral stages of weedy annuals and grasses to more permanent, climax-type perennial forms, with concomitant control of the noxious weed, Russian thistle, Salsola kali var. tenuifolia Tausch., which is the key plant in the development of high populations of the beet leafhopper, Circulifer tenellus (Baker), the vector of curly top disease of sugar beets and other truck crops (Armitage, 1952).

The Mite, Tetranychus desertorum Banks (=opuntiae Banks), accidentally introduced into Australia with prickly pear material from Texas, U.S.A., in 1922-23, was reported to be a valuable agent in the control of Opuntia inermis DC. in Australia before the dramatic success by the moth, Cactoblastis cactorum (Berg.) eclipsed all other species in rapidity and thoroughness of action (Dodd, 1940).

The fungi, Gloeosporium lunatum Ell. and Ev., Phyllosticta concava Seav. and Montagnella opuntiarum Speg. are reported by Dodd (1940, p. 47) as sometimes destroying prickly pear as primary parasites, but he felt that these are not effective agents of control, possibly because their requirements of rather humid, cloudy weather are met in pear areas only occasionally and to a limited extent. He felt that the secondary parasites, or wound organisms, such as "the bacterial soft rot or rots-for more than one organism may be involved-" are more important [than the primary parasites] as an assist to Cactoblastis in the rapid and complete destruction of the plants. Fullaway (1954) reported unsuccessful attempts to control Opuntia megacantha Salm-Dyck. in Hawaii by spraying and inoculating with spores of Fusarium oxysporum Schlect. which cause a disease of the red-fruited form of $O$. megacantha.

Of limited potentialities should be mentioned several miscellaneous forms. Among these are certain higher plants which are parasitic on other plants. Examples are the dodders, Cuscuta spp. (Convolvulaceae) and the broomrapes and witchweeds (e.g., Orobanche, Boschniakia and Striga of the Scrophulariaceae and Orobanchaceae). These may account for a change in plant composition in small local areas. Their limited powers of dispersal and host-finding, combined with a variable status as to host specificity, would seem to preclude the use of many of these forms for the present.

Also, the carp fish, Cyprinus carpio Linn., has been used for control of aquatic weeds (see Sweetman, 1936, p. 382).

Vertebrates such as goats and geese have been used by man for many years in control of weeds in a manner which is perhaps largely akin to mechanical control, since the densities and behavior of these animals are held under the arbitrary control of man and they are not allowed to react, as populations, to changes in the densities of the weeds. For example, large flocks of domestic geese are currently being used as a substitute for the expensive method of 
hand labor in control of certain weeds in cotton and other row crops in California.

\section{THE NATURE OF DAMAGE TO THE WEED}

If the introduction of natural enemies results in the ultimate reduction of a weed's noxiousness, regardless of the nature of the damage to it, and whether the result occurs directly or indirectly, then the attempt is a success, varying in degree with the reduction in noxiousness.

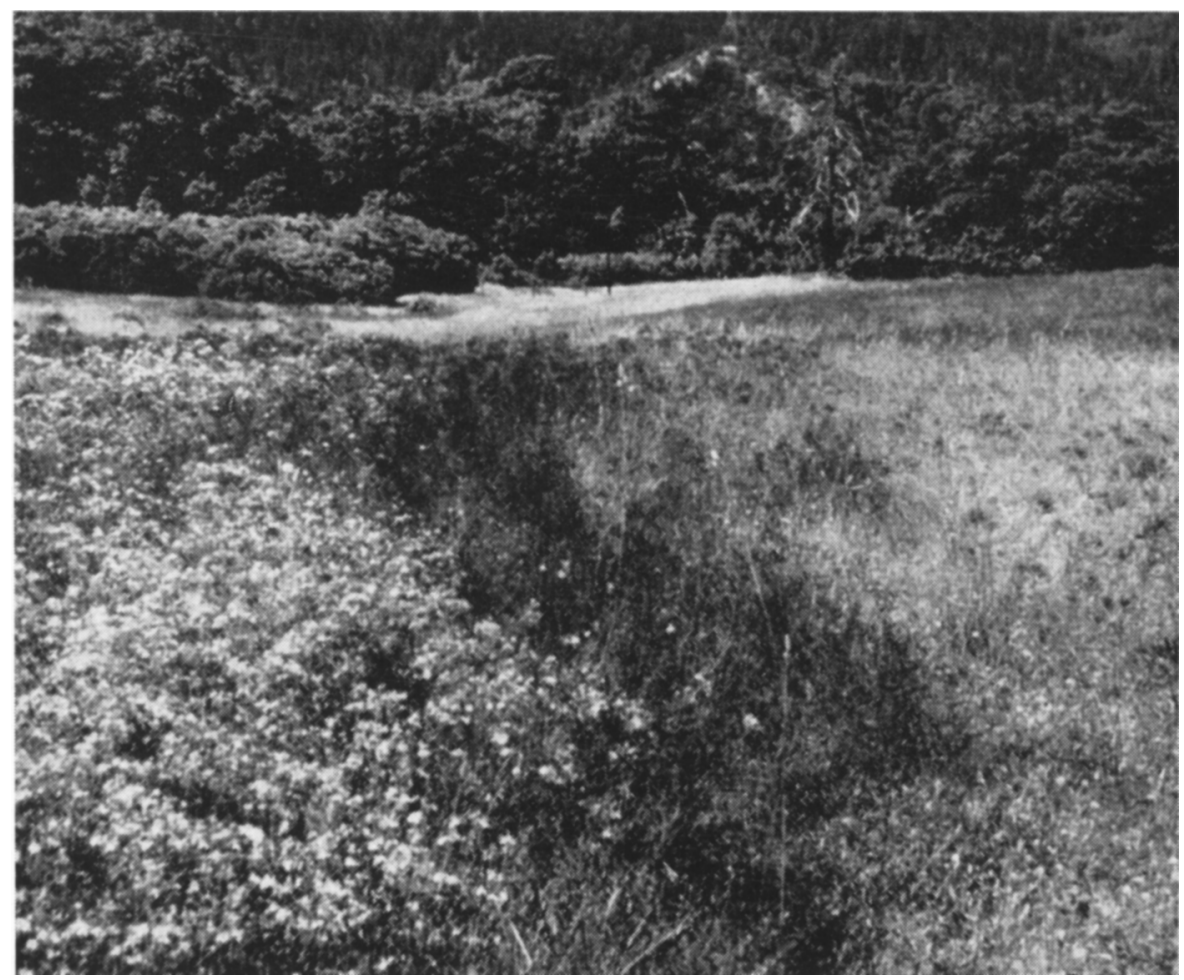

Fig. 3. Biological control of St. Johnswort, or Klamath weed, in California, by the introduced leaf beetle, Chrysolina gemellata (after Holloway and Huffaker, 1949). Left, weed in bloom. Center dark strip, living weed stripped of foliage by advancing adult beetles. Right, field cleared of weed by previous larval activity, with forage grasses returning. Entire field has remained a solid stand of grasses and forbs since 1950.

\section{Direct and Indirect Destruction}

Insects or other natural enemies often destroy individual plants, and, ultimately, stands of a weed through direct destruction of vital parts. Examples are the action of Cactoblastis cactorum (Berg.) on Opuntia (Dodd, 1940; Bess, unpublished) (see figs. 1 and 2), or Chrysolina gemellata (Rossi) ${ }^{4}$ on St. Johnswort (Holloway and Huffaker, 1951) (see fig. 3). There are cases

${ }^{4}$ Various authors have referred to this insect as Chrysomela gemellata Rossi or Chrysomela quadrigemina Suffr. 
where the weed dies very quickly, and others where they do not die immediately from this relatively direct action, but die during another season of the year as a result of impairment of the necessary tissues in performance of their functions at a critical time. Thus St. Johnswort plants, the primary roots of which are destroyed by Agrilus hyperici Creutz. do not die during the period of attack but during the dry summer following attack, a time when soil moisture is not available near the surface. There is sometimes interaction with the factor of competition with other plants in this case (Holloway and Huffaker, 1953).

It is obvious that an enemy may destroy a weed indirectly through: 1 ) ereating favorable courts of infection for primary plant pathogens or forms which are secondarily pathogenic but which hasten destruction, and 2) cancelling competitive advantage possessed by the weed in the respective environment. An example of the former is offered by the account of Dodd (1940) that Cactoblastis cactorum (Berg.) although directly destroying much tissue and many plants, opens the tissues to attack by the secondary parasites previoulsy listed and these latter aid in the rapid destruction of stands of the pear. The control of Clidemia hirta D. Don in Fiji by Liothrips urichi Karny is an example of the latter (Simmonds, 1933, 1934), and to a degree at least, so also is the control of black sage, Cordia macrostachya (Jacq.) R. \& S. by Schematiza cordiae Barber in Mauritius (Williams, 1951). For a discussion of the effects from the lowering of a plant's competitive ability, the reader is referred to the sections on "Plant Food as Limiting Insect Numbers" and "The Role of Insects in Plant Ecology." Simmonds (1934), Wilson (1943, 1949, 1954 and elsewhere), Huffaker and Holloway (1949) and Huffaker (1953) discussed examples of this type of action.

\section{The Plant Parts Attacked}

There has been much emphasis of the action of insects which attack seeds or which bore in the roots or stems. While safety of introduction has been the principal reason for this emphasis (Imms, 1929 ; Wilson, 1943), these authors have also expressed the opinion that these forms are more efficacious. It has not been demonstrated that they are any safer or, indeed, any more efficient. Too few examples among each group have been tried, and there are too many subtle ways by which forms which attack leaves or terminal shoots, for example, may accomplish control, to form a valid conclusion from the few experiences. Also, since this view has been prevalent, the same opportunities may not have been given the other forms.

The point far greater in importance is that whatever the nature of the injury, a really good agent is one which, through direct or indirect action, causes the destruction of existing stands of the weed. Leaf-eaters as well as those which bore in or destroy "vital" parts may be equally important. This author agrees with Chater (1931) and Wilson (1949) in the view of the latter that, "It is questionable if insects attacking seeds or fruits of perennials are normally very suitable insects for introduction, for the host persists unaffected and the control by seed reduction is likely to prove a slow process, especially as vegetative reproduction is not uncommon in weeds and some flowering is likely to occur in periods when the insects are not active." How- 
ever, it cannot be overemphasized that this applies primarily to relatively long-lived perennial weeds.

Insects which attack seeds could prove highly efficient in the control of annual weeds, through preventing spread and replacement. Indeed, such weeds are now receiving attention in this field, and the current effort to control Halogeton glomeratus C. A. Mey. in the western United States and the consideration of control projects on Italian thistle, Carduus pycnocephalus Linn. and C. tenuiflorus Curt., and puncture vine, Tribulus terrestris Linn., in California, and Noogura bur, or cocklebur, Xanthium spp., in Australia are examples.

It may be added that with an example such as gorse, Ulex europeus Linn., the hard-coated leguminous seeds may remain viable for ten to fifteen years or more, and a given plant has a life span of fifteen to twenty-five years. If during that period even a small percentage of the seeds escapes destruction each year, there would undoubtedly continue to be far more than enough viable seeds present beneath the old plant to accomplish replacement at its death. However, Perkins and Swezey (1924) placed much importance on the action of fruit and seed-destroying insects in the control of lantana in Hawaii, as did Miller (1936) in the control of ragwort, Senecio jacobaeae Linn., by the seed-fly, Pegohylemyia jacobaeae Hardy. If spread is a vital factor and great quantities of seed are required this type of injury is important.

\section{The Subtlety of Action}

The manner by which death occurs may be rather subtle and not directly involving the anatomical portions of the plant which are destroyed. Thus, in an experimental arrangement using artificial foliage-destruction of $\mathrm{Hy}$ pericum perforatum Linn. at an intensity and seasonal occurrence simulating destruction by Chrysolina gemellata (Rossi), Huffaker (1953) demonstrated that death is not caused directly by the loss of foliage or in any way involving competition for sunlight. It is the result of the inability of the greatly reduced foliage to maintain a sufficiently extensive root system, associated with the absence of adequate subsurface soil moisture during summer (see fig. 4). When adequately watered during the dry summer subsequent to the time when the beetles cease feeding and enter aestivation, and if the clipping of foliage was likewise stopped at that time, the plants recovered and grew profusely. On the range the struggle for moisture involving the untouched roots, rather than a struggle for sunlight, involving the destroyed foliage, is the key feature. In an environment where competition for sunlight dominates competition for water, converse relations might be expected to apply in certain cases.

\section{Numbers of Insects Required to Destroy a Plant}

An individual plant may survive unless attacked by a large number of insects, or, on the other hand, it may succumb from the action of only one, or a few. In the destruction of a given unit of hosts (given the capacity to destroy at some level of density once contact is made), the larger the production 


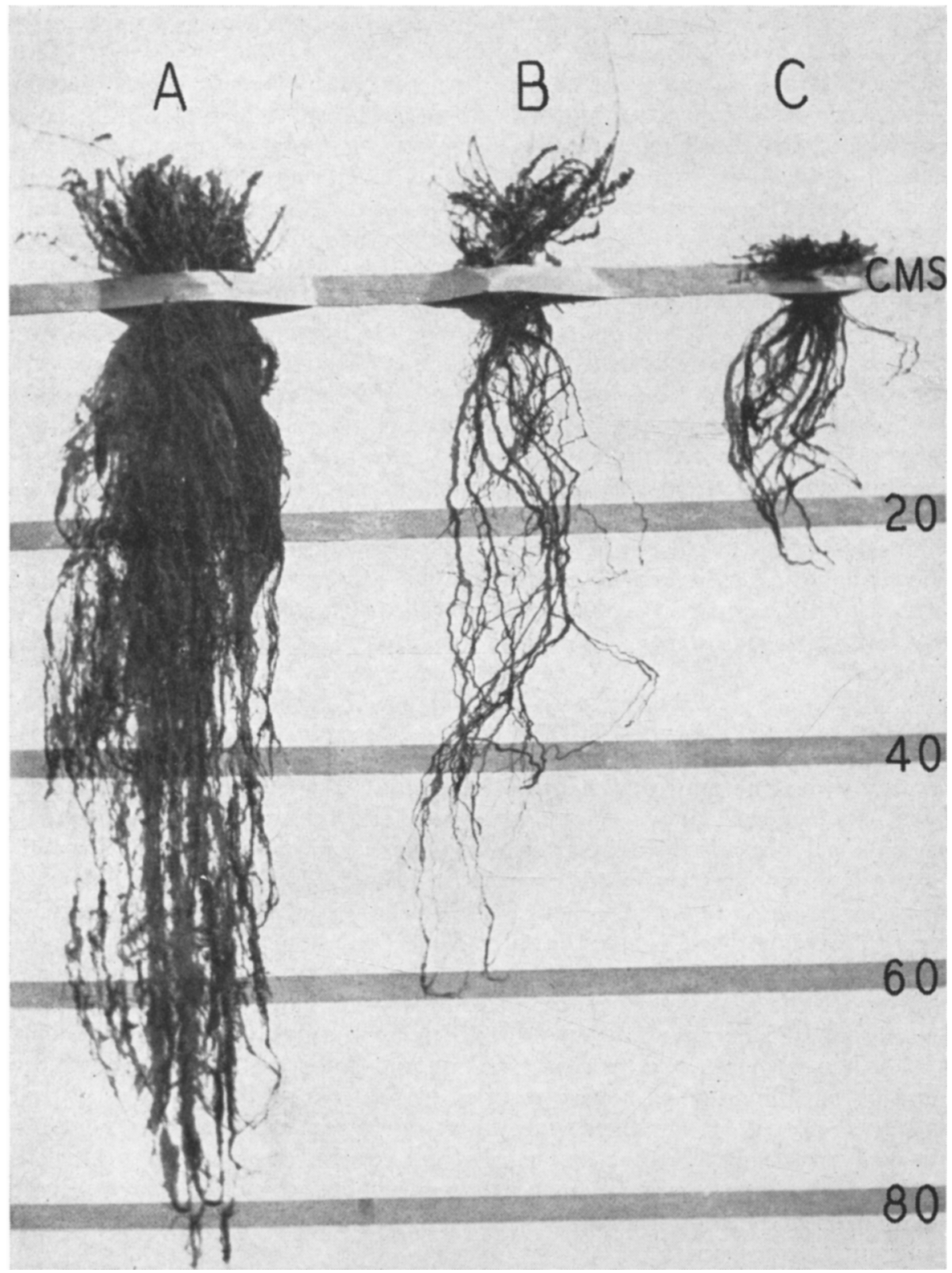

Fig. 4. Extent of root system of St. Johnswort plants is greatly reduced by degree of beetle feeding. Near-complete foliage destruction during period of larval activity of Chrysolina gemellata, coupled with absence of rainfall during summer months, results in death of the plants. Roots produced by: (A), an undamaged plant; (B), a plant with foliage clipped to simulate moderate larval feeding; and (C), a plant with foliage clipped to simulate intense larval feeding - the characteristic field condition. (After Huffaker, 1953.) 
of total effective contacting capacity ${ }^{5}$ the more useful the agent concerned, other things being equal (a largely inconceivable state). This statement is in accord with theory in the biological control of insects (Nicholson, 1933) wherein insects which consume a large number of hosts per individual (and thus only one controlling agent is produced on many host individuals) are considered inferior to ones which consume only one or a fraction of a host per individual. According to this view, entomophagous parasites are more capable than predators since they are maintained as surviving, effectively searching populations at lower host densities.

However, since an inconceivable equality in other capacities of two agents must be assigned in order to evaluate this single attribute, such a comparison is largely meaningless. This question is raised because of the statement of Wilson (1943, p. 81) to the effect that a stem or root borer which consumes or occasions the death of large portions of a plant, and required in smaller numbers to accomplish the plant's death, is a more effective agent than a leaf-feeding insect which destroys smaller amounts of tissue and is required in greater numbers to effect destruction. While it is obvious that, considered from the single viewpoint, that position is unsound, Wilson gave some valid reasons for believing that insects which bore in vital parts, thus occasioning death of additional dependent tissues, are generally more likely to be successful:

"a) the greater damage (per individual) caused to the host plant by virtue of the incidental death of tissues dependent on the eaten tissue." [The significant point is missing. It is probable that because of this more such species do have the capacity to destroy; fewer of them would be of a valueless type-such as the hypothetical example of Wilson (1949) of a stem borer which attacks an annual weed too late to affect its seed-production or competitive power.]

"b) the decay occurring in the host from the development of bacteria and fungi in the insect's frass.

"c) their lesser likelihood of attack by native predators and parasites in the new country."

\section{THE RISKS OF INTRODUCTION AND HOST SPECIFICITY}

The biological control of weeds carries with it serious potential dangers, and precautions matching that seriousness are absolutely requisite. The risks in this work are relative and there can be no absolute guarantees of safety. The risks involved are related: 1 ) to the degree of host specificity and specialization of the agents proposed for introduction, and 2) to the botanical position or special features of the weed. Tillyard (1929a) emphasized that the real risk is due to our colossal ignorance of the nature and extent of host selection and specificity rather than to the method itself. Weeds botanically far removed from economic plants are generally the better risks, but as Thorsteinson (in press) stated, these relationships as such are not so basic as are the specific phagostimulants involved in the chemotactile sense relative to host plant acceptability.

\footnotetext{
${ }^{5}$ An expression of the total numbers of contacting individuals (a single uniparental insect, for example) together with a value for dissemination and host-finding efficiency.
} 


\section{Acceptability of Hosts and Restrictions in Diet}

The work of Brues (1920, 1946), Dethier (1947, 1954), Thorpe (1939), Thorsteinson (1953), Jolivet (1954) and others on the nature of host selection by phytophagous insects shows very clearly that the chemical compounds present as essential oils and alkaloids are important determinants of the acceptability of hosts, together with secondary features such as hairiness of surfaces or physical condition.

Brues (1952, p. 41) stated, "As the presence of each such chemical [phagostimulant] is usually confined to some natural group of plants, they are the ones to which the insects are attracted. When the same chemical attractant appears sporadically in unrelated plants, they also may be chosen." The degree of restriction is quite variable. Dethier (1947) stated that there are probably few truly monophagous insects, while at the same time recognizing that many forms are very restricted in their diets. Brues $(1952$, p. 41) further stated, "The gall insects are quite uniformly oligophagous or monophagous." He also pointed out (1946, chap. 3 ) that plant-feeding members of the higher orders of insects such as the Coleoptera, Lepidoptera, and Hymenoptera possess in general a high degree of restriction in diet; and that many representatives of the lower groups such as some grasshoppers and walking stick insects are likewise far more restricted than is generally supposed. It is sometimes true that the essential phagostimulant. together with suitable physical and other characteristics, may be found in plants very widely separated botanically and the same acceptability not found in plants more closely related to either (see Dethier, 1947, p. 52; Brues, 1952, p. 41).

An example given by Dethier was that of the butterflies, Pieris rapae (Linn.) and P. brassicae (Linn.) which attack a wide variety of genera, mostly Cruciferae, but which also attack Tropaeolum [Tropaeolaceae] and Reseda [Resedaceae]. The latter two plants have essential oils similar or identical to the mustard oils. The example is somewhat dulled by the fact that these insects were also found to attack "certain few other plants not known to contain these oils." Dethier also stated that larvae of Papilio ajax Linn. should be attracted to Solidago and certain other genera far removed from the Umbelliferae, based upon the presence of the same specific attractants; however, he stated that the presence of fleshy leaves, pubescence, et cetera, may come into play and prevent their utilization as food. This latter is an important consideration in biological control of weeds.

Dethier (1954, pp. 40-43) emphasized that the specific phagostimulants in a plant may "... vary with the time of day, the seasons, the growth stage of the plant, the tissue, climate, and soil conditions." He further stressed that hybridization and polyploidy may greatly alter these characteristics. Yet, he also stated that in studies of forced altering of diets, “... the more restricted a species is in its feeding, the greater the difficulty in altering its feeding habits."

Therefore, it is obvious that although recent work lends hope that it may become possible to predict which plants would be acceptable, such prospects are far in the future, and the laborious method of conducting starvation tests on all conceivably prospective host plants of importance must be continued. 


\section{Records of "Changes in Diet"}

Much has been written (Perkins and Swezey, 1924 ; Imms, 1929; Essig, 1948; Tillyard, 1929a, and others) concerning the possibility that insects introduced to control a weed may become pests of desirable plants, and many instances of "remarkable" changes in diet have been cited. Dethier (1947) was of the opinion that most cases of such "changes in diet" represent reversions to an ancestral habit rather than involving inherent genetic change in host acceptability.

The instances which have been stressed do not represent a serious challenge to this method of weed control. Both Wilson (1949) and Williams (1954) concluded that where full precautions are taken, the entomologist is certainly assuming a permissible risk in the introduction of phytophagous insects to control a serious weed. Wilson emphasized that there is no greater chance that a genetic change will occur in an introduced species occasioning it to adopt new and valuable hosts than that such will occur among our thousands of presently innocuous plant-feeding species. The latter author and Huxley (1954) stated that constancy of habits and stability rather than change are the rule in nature. Also, Painter (1951, p. 110) stated that the fragmentary evidence relating to examples of "changes in diet" fall into three categories: "(1) The old and the new hosts were both within the range of behavior reactions and physiology of the insect, (2) a change has occurred in the behavior pattern of the insect by way of some form of learning or by mutation, and (3) a change has occurred, by way of mutation and selection, in the physiology of the insect so that it can utilize the new host plant as food." However, it is significant that he also stated, "... there seems to be no reason for thinking that physiological characters concerned with food, such as those that form the basis of most resistance, may be any less permanent than the morphological characters with which the entomological taxonomist deals."

In illustrating the evolutionary pattern of certain changes in diet by forms ancestral to some of our extant highly specific food consumers, Brues (1946, p. 94) cited the example of the subfamily typified by the genus Epilachna which alone among the ladybird beetles (Coccinellidae) is vegetarian, the others being predatory almost entirely on aphids and scale insects. Regarding the species of Epilachna, Brues (pp. 94-96) stated,

"They are, indeed, just as highly specific in their choice of food plants as the most fastidious vegetarian insects who can proudly trace their distaste for flesh as far back as Mesozoic times. As a matter of fact in this instance it probably does extend into the Tertiary, perhaps some threescore millions of years ago, for Epilachna is now almost cosmopolitan, with species in Europe, Asia, Japan, Malaya, Australia, Africa, and South America. All are vegetarian, but as we pass around the world the exotic species bring other plants into the picture, Solanaceae in the Orient and members of the cotton family (Malvaceae) in Africa. This interesting group undoubtedly underwent a shift or mutation in food habits at some time in the dim past. Since then it has encompassed the globe, undergoing minor changes, but clinging persistently to the 
changed diet. Such behavior shows the near immutability of the instinctive processes in insects, broken only at interminable intervals by some cataclysmic mutation."

Brues also stated (1946, p. 96):

"The terrestrial flowering plants are the sine qua non of the insect tribe for it is among the insects that feed upon these that phytophagy reaches its highest development."

Brues pointed out that man is so accustomed to his own quite varied vegetable menu and to the somewhat comparable variety in diet of the large grazing vertebrates, that he is often startled to learn of the fastidiousness or high degree of selectivity exhibited by many of the insects which feed on plants, or, for example, of the equally close restriction of the primitive Australian marsupial (Phascolarctos cinereus (Goldf.)) to the leaves of a particular species of eucalyptus. In fact, Brues stated, "Among insects this kind of restriction to a single species of food plant or to a series of related species is by no means rare and insects which do not show some such preference are the exception rather than the rule."

Generally, the cases of changes in diet which have been cited by various authors involve oligophagous species whose hosts have simply become better known as entomology has advanced. It is felt that these were never at any time insects which were closely circumscribed to a single plant or group of closely related species. Any insect not so circumscribed would never pass the stringent requirements of present-day programs. Essig (1948) cited no specific references in the text, but cautioned against the possibility of species changing their food habits from a closely restricted condition to one of wider range. He listed the case of cottony cushion scale which was reported to have attacked only "Acacia, Pittosporum, Casuarium, Grevillea, Hakea, and possibly other native Australian plants," but when introduced into other parts of the world quickly broadened its dietary range to include Citrus, Rosa, Prunus, Robinia, Faurus, and other plants. It is obvious that there should be nothing surprising in the inclusion of many other plants of a new environment in an already quite varied diet. Dethier (1947) is of the opinion that polyphagous species will feed on any host plants not either actually repellent to them or physically unacceptable.

The matter of adaptability in the form of adequate seasonal synchronization is important under field considerations, as illustrated by the segregation of racial types synchronized to utilize some host not normally attacked by another population of the same species which attacks hosts which have a different phenology. The case of the codling moth, Carpocapsa pomonella (Linn.), which normally attacks only members of the Rosaceae, and which developed in California a race which attacks Persian walnuts (Juglandaceae), is cited by Smith (1941). It is of interest to note also that Quayle (1926, p. 14) cited an example of this insect attacking oranges (Rutaceae). Thus, the potential spread in diet of this insect encompasses three distinct plant families and is not nearly so restricted as is indicated by its usual limitation to apples and other plants of the rose family.

Imms (1929) cited the case of the cosmopolitan Vanessa [= Pyrameis] cardui (Linn.) which had been known as feeding almost exclusively on 
Carduus and Urtica, but had recently attacked Lupinus in Poland and attacked peppermint and soybeans in Michigan. Yet, Essig (1926, p. 645) had previously stated that the caterpillars of this butterfly feed on thistles [Compositae], malva [Malvaceae], amsinckia [Schrophulariaceae], burdock [Polygoniaceae], lupine [Leguminoseae], nettle [Urticaceae], marshmallow and weeds [various], but when abundant also attack the globe artichoke, beans, sunflower, and prune [Rosaceae]. Imms' use of this example was obviously a poor one for his purpose.

Imms (1929) also listed several other examples of insects with restricted diets which changed hosts or adopted new hosts. "Thus, larvae of Vanessa butterflies such as io, c-album, and urticae which are more especially associated with nettle (Urtica) are known to be able to feed upon hop (Humulus ), which, however, is closely related to their usual host-plant." The last part of the sentence shows that this example, also, is not pertinent. Imms also stated, "The Lycaenid, Cyaniris argiolus, which feeds upon the young leaves and flowers of Ilex [Aquifoliaceae], Hedera [Araliaceae], Rhamnus [Rhamnaceae], and Cornus [Cornaceae] has been observed in Finland boring into the unripe fruits of black currants [Saxifragaceae]." The fact that it was previously known to feed upon both young leaves and flowers of species belonging to members of several unrelated plant families should have precluded surprise that it attacked young, green fruits representing still another plant family. Another example given was that of the capsid bug, Plesiocoris rugicollis Fallén, which commonly attacks Salix [Salicaceae] and less frequently Alnus [Betulaceae], Myrica [Myricaceae], and Corylus [Corylaceae], later becoming an economic pest of apple [Rosaceae] and currants [Saxifragaceae]. Thus, two additional plant families were added to the four already known to be hosts.

Still additional examples are discussed by Imms (1929) relative to changes in diet of an unusual and unexpected nature: Schroeder (1903) and Harrison (1927) force-reared certain insects (e.g., the sawfly, Pontania salicis [presumably=Nematus salicis (Ashm.)] on species of Salix (willow) other than their normal Salix hosts, and subsequent generations preferred the new hosts or even rejected the original hosts altogether. This is a verification of Hopkin's host selection principle, but, obviously, the original population was sufficiently heterozygous that it was successful on Salix as a host. It was not a monophagous insect. The resultant selected population may have lost the necessary heterozygosity to reaccept the original host.

Imms was aware that many of these dietary changes were not serious indictments to the biological method of weed control, and it seems that he cited them primarily to show that such changes have been associated with external, unspecialized feeders on leaves or flowers. He was emphasizing the supposed greater safety with the use of root or stem borers or of seed feeders.

\section{The Relative Safety of Different Types of Feeding}

In this latter contention, Imms also seems not to have been on well-founded ground, although he may eventually be proved correct. Dethier (1947) stated, "Nowhere is the role of attractants which guide insects to their proper food more complex and outstanding or the attractants more specific in action than 
in the lives of plant-feeding insects," and, further, "This is especially true as it relates to those insects which feed on leaves." However, he also stated, "Of borers which attack living trees or sound wood, many exhibit as decided preferences as phytophagous [presumably he meant leaf-feeding] insects," and "most attractants operating in the lives of borers are ovipositional in nature..." These and subsequent statements that very little information is available show that Imms overstated the ease against leaf or flower feeders in biological control as contrasted to root or stem borers or seed-infesting forms, viewed from this aspect alone.

Wilson (1943) followed Imms in his view that insects which do not feed on leaves or flowers but which bore in roots, stems, fruits, or seeds are preferred due to greater safety and greater chances of success in their employment. Wilson later (1949) particularly questioned the view that seed-infesting insects may offer better chances of success. The question as to whether there is greater safety remains unanswered. It is the degree of specificity demonstrated by the particular examples, rather than the general dietary focus which is important. Imms' conclusions on which his point was based have been shown to be the product of poor examples. The question of greater likelihood of success has been discussed previously.

It is obvious that efforts to find insects which are specific to particular weeds and therefore safe prospects should cover all possibilities without undue emphasis on the particular part of the plant attacked, and, by rigid starvation and ovipositional tests, to demonstrate the safety in introducing tested examples. The widest possible representation of economic plants should be included.

\section{Other Factors Affecting Specificity}

Aside from chemical unsuitability, a plant may be unsuitable by reason of not possessing the necessary physical characteristics to release ovipositional behavior, or to serve as food and abode. Tinbergen (1953) has shown that many complicated behavior patterns of animals are instinctively set in motion only by a reception of some simple releaser stimulus. These may be either physical or chemical in nature or both. Thus, Currie (1932) showed that the peculiar seed covering of Xanthium burs satisfies the requirement for oviposition of Euaresta aequalis Loew. The females would likewise oviposit on artificial burs made of rubber and small pins which simulated the physical structure of Xanthium burs.

Likewise, insects may be restricted from utilizing any plants which are not in phenological synchronization with special features of their life cycles, as previously mentioned, or if an intimate insect/plant-hormone relation is involved. These points are discussed further under the topic on "Starvation Tests," particularly with regard to examples which may safely be excluded from extensive testing.

Also, the ways of reducing the risks are summarized under the section on "Procedures."

\section{THE BALANCE IN NATURE}

A number of important concepts and desirerata in the biological control of weeds are primarily ecological in nature. The chances of successful ventures 
in this field are fundamentally associated with the forces for balance in nature. The several aspects, although interrelated, are discussed separately, with some of the divisions made more on practical than on academic grounds.

\section{Changes in Abundance}

There is a pressing need for some common meeting ground in the consideration of measurements of abundance of plants and animals. For example, in studies of population changes occurring under interactions of plants and insects feeding on them, we need to express changes in both plant abundance and insect abundance as reciprocally related phenomena. Since 1947 Huffaker and Kennett (unpublished research) have conducted an extended study of such changes in abundance associated with control of St. Johnswort, or Klamath weed, Hypericum perforatum Linn., by the leaf-feeding beetle, Chrysolina gemellata (Rossi). Huffaker and Kennett (1956) published striking results of reciprocally dependent oscillatory changes in vigor and mass of growth of strawberry plants and densities of cyclamen mites feeding on them. Dr. Frank Pitelka, ecologist of the University of California, has suggested in private conversation that some such interaction involving the small arctic rodents and their plant food may be the explanation of the recorded but unexplained cyclic fluctuations in abundance of those animals. Little attention has been given to the quantitative and qualitative changes in the plants upon which they feed. However, Pepper (1955) presented an example wherein the interdependence in numbers of grasshoppers and the specific composition of range vegetation is emphasized. It should not be overlooked, however, that, as Wilson (1950) stated, "The insect and its primary parasites may mutually determine their populations at a level below that which permits the host plant and phytophagous insect to have such a mutual relationship."

Plant ecologists and animal ecologists have proceeded along different lines toward their considerations of density perhaps primarily due to the definitiveness of an individual animal and the lack of this definitiveness in plants. The use of the concepts of plant density, coverage dominance, root dominance, basal area, frequency of occurrence, et cetera, is an effort to describe plant densities in the broad sense in quantitative or census units. The inability to count individual plants in every case and the much greater variations in size and importance of the individuals, with extensive vegetative proliferation, in contrast to the case with animals, have led to somewhat divergent approaches to and explanations of the causes of abundance in the two fields. There is no reason why plants, as much so as animals, are not subject to comparable density-dependent actions, with density-independent, largely fortuitous conditions setting the limits or potentials within which these occur. It does not change fundamentals that in one field or in certain arenas, the changes in the physical conditions may dominate such changes in abundance as are observed, while in the other field, or under other conditions, changes due to competitive or biotic, inhibitive actions may be more obvious.

In this paper, the term population is used in a very broad way to include both plant and animal abundance. There is no compelling reason why the causes behind the quantitative presence, importance, or abundance of plants 
in a general area should be viewed as inherently different from those of animal populations. It is more appropriate and fruitful to view the components of the entire biotic complex or biome as interdependent to the greatest degree, and that both the plant and animal densities are intimately related one to the other and governed by the same principles.

Perhaps oversimplified, the physical environment, its changes being largely fortuitous and density-independent in occurrence, directly or indirectly furnishes or conditions the supply of all requisites to population or abundance of life; while for any stable or determinate level of limiting requisites, there occurs competition (auto-inhibition or density-dependent actions) for those requisites and this competition results in a constant tendency to regulate levels of abundance and the patterns of change short of full saturation. It is particularly significant in cases where the requisites are reactive to density (Huffaker, in press $a$ ).

The dominant influence of the physical environment over the patterns of competitive actions, with these operating within the limits set by the physical conditions, becomes very clear in the consideration of vegetation or of insects inhabiting very hazardous and widely fluctuating environments, and in considering cases where the common ceilings to density are fixed, irrespective of density itself. An example of the latter is the case where the abundance of a limiting requisite, such as nesting sites, is uninfluenced by density. Therefore, it is obvious that the changes in the physical environment (the supplier of the requisites) is a part of the determining complex, just as much so as is competition for those same requisites. For a full discussion of this view, the reader is referred to the work of Huffaker (in press $a$ ).

This concept represents a modification primarily of the views of Nicholson (1933, 1954) and Smith (1935), with certain differences of emphasis and clarifications considered in the light of arguments advanced by various authors who have emphasized the role of the physical factors in the determination of numbers (Uvarov, 1931; Thompson, 1929; Andrewartha and Birch, 1954). This view incorporates established facts and the most compelling deductive arguments advocating the importance of both density-dependent and density-independent actions. These forces are thus viewed as supplemental, not in any sense as contrary explanations of abundance. Since competition is a concept which is superimposed upon various direct causes of death such as starvation, exposure, desiccation, et cetera, death may at the same time result directly from desiccation, indirectly from competition for the limited habitats having adequate moisture, and still more indirectly, from the action of weather in depleting the supply of such habitats. Different workers have selectively emphasized the particular aspects of interest to them.

To illustrate, there are many examples among the insects which inhabit environments where the changes in the physical variables are marked and frequent and, consequently, the inherent trend of competitive regulation toward equilibrium for any given level of a limiting requisite is short-circuited, or the level of the limiting requisite, or the particular kind of requisite which is limiting, changed so frequently that there is exhibited only wide fluctuations in density, in essential agreement with weather fluctuations, for example. Students of such populations have emphasized the influences on 
natality and mortality without much concern with effects of density itself on population trends.

Likewise, plant ecologists and botanists who work in a field at least one step closer in dependence upon the physical environment have emphasized such factors as soil, sunlight, rainfall, atmospheric aridity, temperature, and phenological aspects of the supply of these as dominant causes of changes in the composition and structure of vegetation, as they create ceilings of limiting requisites. They have recognized but relegated to a correlated position, the role of competition for those requisites in determining which species prevail and their respective abundances. This is just a case wherein the supplier of the requisites, in being more frequently and violently critical, dominates the competition for those requisites in the conspicuousness of the causes of such changes as are observed. The potential limits which are set within which competitive actions must occur fluctuate so much that the competitive regulation within seems trivial. Its role remains the same. Also, studies on the role of insects, rodents, and the larger herbivores in determining the levels of their own plant food supply within these limits, are likely to force a change in viewpoint toward a greater primary recognition of competitive explanations. These influences of a reciprocally dependent nature may be far more dominant than heretofore recognized by plant ecologists.

The eminent authority on food relations of insects, C. T. Brues (1946, Chap. 3), presented a very interesting discussion of the nature of phytophagy among the insects. He considered that the flowering plants and the insects have evolved in especial inter-relationship, and that to a far greater degree than is so with respect to man and the higher vegetarian vertebrates, the insects fill selective roles of control of, and dependence upon, specific plant species. He states, "... insects frequently multiply at such an excessive rate that they may destroy immense quantities of their food plants. This happens in spite of the large number of prolific animals and microörganisms that prey in turn directly upon the insects and serve to check their multiplication. Under natural conditions insects are a prime factor in regulating the abundance of all plants, particularly the flowering plants as the latter are especially prone to insect attack." This latter statement is in contradistinction to prevailing opinion of most plant and insect ecologists. Ecologists concerned with the biological control of weeds take sharp exception to the prevalent opinion and agree with Professor Brues in this respect, some of the reasons for which are stated in the present paper.

As an example of an interrelated situation, the case of biological control of Klamath weed, or St. Johnswort, in California may be cited. Bentley and Talbot (1948) and many other botanists rightly consider that the fortuitous changes in rainfall and temperature from one year to another condition the patterns of germination and establishment of seedlings of the many annuals occurring on the open ranges of Northern California. Hence, the respective intra- and inter-specific patterns of competition and their effects are determined by such fortuitous events as set the levels of the resources. Klamath weed, Hypericum perforatum Linn., recently thrived as a perennial and very noxious weed in this region where, otherwise, the vegetative cover is one of winter annuals-grasses and forbs of greatly varying composition. While the 
introduced leaf-feeding beetle, Chrysolina gemellata (Rossi), has effected remarkable control of this weed and is holding it at a general equilibrium position which is only a tiny fraction of its former abundance (Holloway and Huffaker, in preparation), the local changes in this weed's abundance at its present very low density, even though it is a perennial, are not dominated completely by density effects, either of the weed or its controlling agent, the beetle.

Fires, severe overgrazing, soil disturbance, excessive unutilized growth creating litter, the patterns of sunlight, rainfall, temperatures, and edaphic conditions are known to influence germination as well as the subsequent results of competition among the many species whose seeds germinate. This may be very significant as to whether the weed succeeds in reëstablishing itself at local arenas on the range and to what degree it does so at a given time. But in this case the beetle has the upper hand and prevents the weed from ever regaining its original status, because it operates so effectively at higher levels of weed abundance.

An annual weed would obviously be more subject to significant effects of fluctuations in weather, its potentials of germination and survival upon which a controlling natural enemy would depend would be a more instrumental feature in its changes in abundance, with any reciprocally interdependent actions between such a weed and its controlling natural enemy operating within such fluctuating potentials. The potentials of recovery of animal populations from positions of catastrophe or relaxed pressure from a given cause are in a similar way relatively more dependent upon patterns of weather and less so upon intensity of competition, but the latter is nevertheless present, and increasingly so as density increases.

\section{The Premise of Reëstablishing Balance by Introduction of Natural Enemies}

Williams (1954) stated rather inappropriately an otherwise sound premise in biological control, "The theory that underlies the biological control of weeds is relatively simple and is applicable only to alien weeds. It postulates that the great increase of reproductive rate and vegetative vigor that a plant may show after its introduction into a new country is due primarily to a lack of natural enemies, implying that in its native country its comparatively innocuous status is maintained by such enemies ...," and also, "In other words, the more excessive the growth of an introduced weed, the more likely is the cause to be an absence of natural enemies, and the chances of controlling it biologically are correspondingly higher." Wilson (1949) correctly agreed with this latter statement.

The question as to whether only alien weeds may be proper subjects will be discussed later.

Huffaker (in press $b$ ) stated:

"There is no complaint with the view that in the case of weeds which reach excessive abundance when introduced into a new country, the reason may be due to an absence of natural enemies, and in whatever event, there is greater likelihood of a successful outcome in the introduction of natural enemies to control them, even if their excessive 
abundance in the new country (compared with the original) were not primarily due to an absence of natural enemies in the new home. However, even a relatively ineffective natural enemy in an original environment where potentials of abundance of the weed are very restricted may prove a very effective agent of control in a new environment composed of quite different biotic as well as physical attributes, and where the host plant may reach much higher levels of abundance (Wilson, 1949). In the new environment the host-density threshhold for effective action of the natural enemy may be surpassed while in the original home it is not.

"While aggressive and abundant alien pests are always good prospects for biological control, it does not follow and is ecologically unsound to postulate that such aggressiveness and abundance in the new land is necessarily due to an absence of natural enemies. There are far too many other reasons why a pest may be relatively innocuous in its native land yet aggressive and troublesome in environments new to it. Williams seemed well aware of this but, unexplained, the 'premise' has led to erroneous inferences."

A few extracts from the work of Wilson (1950) explain these relations exceedingly well.

"There is a marked tendency for plants, as for animals, to be far more successful, numerically, in a new environment than they are in the areas where they are indigenous. Where this is so, there are a number of conceivable reasons for it. The new area could be more suitable in soil and climate than the original environment. The competition that the weed meets from other plants could be less intense. The agricultural practices of the farmer in the new country could favour the weed:... Finally, and perhaps most important, a plant, by migrating to a new environment, often escapes entirely from a whole series of organisms which live at its expense, and the absence of these natural enemies in the new environment may enhance greatly its opportunities for survival and increase.

"Nevertheless, it does not necessarily follow that insects in their native habitats play as important a part in the control of their host plants as the example of Cactoblastis indicates they can in new countries."

This question will be returned to under the topic, "Environmental Fitness and the Choice of Agents."

\section{Plant Food as Limiting Insect Numbers}

This topic is interrelated with the next. Such leading theorists as Muir (1914), Thompson (1929), Bodenheimer (1930), Smith (1935) and Imms (1937) appear to have agreed that the numbers of phytophagous insects are only rarely limited by a shortage of their plant food. ${ }^{6}$ If this is true, then generally they do not vitally affect the success or survival of their plant hosts, for if they were capable of so affecting their hosts' success, they would reduce

\footnotetext{
${ }^{8}$ However, these men have not agreed as to the reasons for this. They would differ in particular as to whether the natural enemies [which would not be introduced] of the phytophagous insects normally present in regions where the latter are endemic, are a key feature.
} 
their hosts' numbers to such low levels that they would themselves in turn be limited by the scarcity of food and the difficulty in finding it. The premise upon which entomological control of weeds rests is just the reverse of this. To be a useful natural agent of weed control, an insect must be capable of inflicting, directly or indirectly, decisive destruction of its plant host, thus determining the latter's abundance, and, reciprocally, its own abundance is then adjusted to the abundance of its plant host.

Bodenheimer (1930) opposed the general thesis of a "struggle for existence" with food as a limiting factor. Imms (1937) also stated, "It must be recollected, as W. R. Thompson has pointed out, that although insects entail a vast amount of destruction to economic plants, they rarely cause sufficiently vital damage which will affect the survival of well-established species to a marked degree." Smith (1935), although opposing the general thesis of Bodenheimer [and of Uvarov (1931)] that biotic agents are of little importance in contrast to the physical environment, stated, "So far as actual starvation is concerned, I agree with Bodenheimer that this happens only in rare, borderline cases. Usually other environmental factors limit the density of a species before its food supply is exhausted, or it is exhausted only as a result of an oscillation of great amplitude, not because of a high average density."

On the other hand, among the leading theorists in these fields, Nicholson (1933, 1954) and, to a degree, Uvarov (1931, p. 161), both of whom have made extensive studies of the importance of food, have recognized that it is not uncommon for food to be limiting for a population. ${ }^{7}$ The important similar conclusions of Brues (1946, Chap. 3) have already been cited.

There are a number of reasons why earlier workers tended to disregard the role of plant food as a limiting feature for phytophagous insects. In part, of course, they are inherently correct. The present author feels that if natural selection had not thousands of years previously produced many biotic checks, such as predaceous and parasitic species and pathogenic microörganisms which control the phytophagous insects, the latter would have produced such drastically different pressure, of a selective nature, upon their respective plant hosts, that the present assemblages in our vegetation, and even the resulting assemblages of the higher animals supported by it, could hardly have resulted in the biomes as they exist today. For these phytophagous insects had a prior opportunity, and were in many cases, but not in all (for evolution is a continuing thing), held in check and prevented from too severe pressure against their plant hosts by the natural selection of forms capable of checking them; and, of course, if their pressures were too ruinous to their own survival, it is felt that that too would have been selected against.

Hence, as Huffaker and Kennett (1956) stated, it is expected that the balance in nature is characterized by: 1) some examples wherein suitable habitats or abodes, with adequate protection or preclusion against enemies or adversities of the physical environment, is limiting, and 2) other examples wherein competition for food is the dominant limiting feature. It is possible that the first listed more commonly checks phytophagous insects than does the latter, but this is not established.

\footnotetext{
${ }^{7}$ Uvarov, however, attributed to climate the real importance as the determinant of the level of food.
} 
On the other hand, there is much evidence that the impression that food is seldom limiting for phytophagous insects is misleading. First, the fact that host plants may be commonly present but not nearly so commonly suitable, or suitable at all potential nourishing areas on a plant may have been one of the reasons why observers have often concluded that plant food in nature is seldom limiting for insect populations.

The work of Franz (in press) illustrates the subtle way in which phytophagous insects may be checked by their food supply and, as well, the interaction of their feeding and the recuperative power of the plants upon the determinative action of predators. Although native predators may accomplish control of Adelges piceae (Ratz.) during the spring months, the destruction of the phellogen and phelloderm cells in the plant by the feeding of the chermesid, in the event that populations reach high levels, sets an upper limit to density and duration of an infestation. Trees which have suffered attack for several successive years no longer maintain the chermesids, although a secondary phellogen develops in the deeper layers of the bark and this may in time give rise to a secondary population cycle.

There have been a number of other important studies during recent years which have emphasized the importance of specific nutritive elements in the diets of insects and the great dependence of many species upon their obtaining not only adequate quantities of food, but food containing precise balance of nutritive elements (Painter, 1951 ; Rodriguez and Rodriguez, 1952 ; Fleschner, 1952; Hagen, in press). It is obvious, therefore, that the mere presence of a host plant, or the parts attacked, is no assurance that any quantity of suitable nutriment is available for a phytophagous insect. Plant parts normally attacked by a form which does not devour gross tissues may be equally abundant at two different times or places, yet the amount of usable food obtainable in excess of the amount utilized in finding and securing it, in the one case may be nonexistent or limited to a few microarenas on very few plants, while in another case the suitable nutriment may be largely coexistent with the presence of the plant parts containing it. This seems to be especially pertinent with regard to aphids or phytophagous mites, for example.

Secondly, the general impressions have been based only upon the obvious, and this is often misleading. In nature, plant hosts of insects are at the same time and place suffering attack by the insects and experiencing a resultant decreased ability to compete with adjacent plants-a relative increase in competitive pressure. As the plant ecologist normally has not evaluated the role of the insects feeding on the plants, so have the entomologists formed their views without full evaluation of the complex of selective phytophagous insects along with and including the role of competition by other plants. A small advantage lost to a plant as a result of insect attack, combined with the action of its plant competitors, may be enough to account for its general control or low abundance over extensive areas. The point is of course that that low abundance, even as an indirect result, may be regulated by the insect and limiting for it in turn, although the evidence is often subtle.

In most natural vegetation relative equilibrium or rough balance already exists between such hosts and their phytophagous enemies in the cases of those which may be significantly affected by such enemies. The action of the 
insects at such a time would not seem superficially to affect the survival of such plant hosts or the density of the stands to any marked degree; but, nevertheless, even with a minor pressure, might be exerting just the necessary action in holding the plant host at its respective position, and capable of intensifying that action if the host were to increase appreciably. Yet, it is at this same low position that it is markedly affected by weather adversity and difficulty of finding hosts, such that a balance is struck at a position where factors other than reciprocal dependence of the phytophagous insect and its food plant might well account for greater changes in intermediate, temporary fortunes of either the insect or its host. But these causes and the changes themselves are incidental to the superimposed reciprocal, densitydependent control.

Conjecture relative to the case of Klamath weed is very pertinent. Four species of insects from Europe have been established in California (Holloway and Huffaker, 1952, 1953). Two feed on leaves, one attacks the roots and one is a gall-former. They are very different in reproductive capacities, modes of life, and nature of destructive action. Yet, each of them has in places demonstrated a capacity to reduce stands of this weed to a point of little economic significance. It is believed that in the absence of knowledge of the history of this weed and unless he made specific detailed studies, a trained entomologist or ecologist would conclude, even after close observations of ranges cleared of the weed now for seven consecutive years, that the dominant insect species, Chrysolina gemellata (Rossi), is not a significant influent of the stand of vegetation and that the few plants of Klamath weed seen here and there are not primarily limited by this insect. He might also erroneously conclude that this plant is a shade-loving species, since the beetle checks it much less effectively under shade.

The action of the gall fly which does not destroy quickly and directly would under such circumstances be unsuspected. Also, the action of the root borer is chronic, effecting accumulative and largely subtle attrition. It destroys the main roots during the fall and early winter but at that time surface feeding roots often keep the plant looking well due to the abundance of surface moisture. During the following dry summer when the plants die because they no longer have the necessary depth to their roots, the borers which destroyed the roots have emerged and those plants harboring the young larvae or eggs of the next generation are healthy. Also, the plant is a perennial, and increases in density fairly slowly at times. The borer destroys a given percentage of plants the first year, a percentage of the remaining plus some of the few new plants the following year, et cetera. The effect any one year might not appear to be decisive, but, accumulated, accounts for destruction of stands (Holloway and Huffaker, 1953).

The third important way whereby the misleading impression regarding the role of food may be clarified involves the academic or geographic theaters in which researchers of divergent views have worked. The author is indebted to J. K. Holloway for his contribution of the nucleus of this idea.

As Smith (1935) stated, many seemingly contrary statements may each contain a large amount of truth. Thus, Uvarov (1931, p. 161) presented the view that climate is the key to the problem of insect abundance and such 
balance as exists, yet he also stated, "No one will deny the controlling value of these factors ..." [natural enemies and shortage of food], and, again, "any temporary deviations in the climatic factors, however slight they may be, affect the percentage of survival, either directly, or indirectly [through natural enemies and food-plants], and thus influence abundance." It is obvious that he recognized that food may become limiting, as certainly it often does with such populations as grasshoppers which were examples much studied by him, but he chose to look beyond the food to the meteorological conditions altering levels of food. Huffaker (in press $a$ ) has emphasized that this is an expected viewpoint in cases where the researcher bases his views on populations of violently fluctuating environments where the levels of the requisites, including food and shelter, are therefore also subject to violent fluctuation. There are also involved two different views of what is meant by "balance." The emphasis in mild, even environments would be on the level of the requisite itself and biotic interdependencies, not on the rather constant physical conditions which permit rather constant potentials of the requisites. Neither view can be regarded as inherently wrong, although the emphases are different!

The next section is devoted to proved examples wherein the plants serving as food for insects (or other biotic agents) are limiting for them, but this is turned around, and the role of the insects on their host plants is emphasized instead; but it should be remembered that the relation is a reciprocal one.

\section{The Role of Insects in Plant Ecology ${ }^{8}$}

Under this topic, it is desired primarily to emphasize the very limited state of our knowledge concerning the force which insects may exert over the destinies of their plant hosts, and to present the evidence as a very potent argument that employment of insects and related phytogenous organisms in the control of weeds is a sound procedure.

Ecologists have been slow to investigate this field. Practical entomologists in the field of biological control of weeds have pioneered here. The attention customarily given by ecologists to the action of insects on plant life has been to pollination, the culture of fungi and other "gardens" by ants, transmission of diseases, agents of seed dispersal, or as temporarily destructive, in the form of "outbreaks," to forests or ranges. They have given little attention to the role of insects in the determination of the composition and structure of vegetation or their role in succession.

The statement of Brues (1946, p. 90), previously cited, that the insects are a prime factor in regulating the abundance of plants is worth repeating at this point, as it carries the weight of a lifetime of observation and study, and is the conclusion of a scholar who is not engaged in biological control of weeds.

Wilson $(1949,1950)$ presented a thought-provoking analysis of the evidence, and Huffaker and Holloway (1949) emphasized certain examples. Much consideration has been given to the influence of man, the large herbivores, and various rodents, on the nature of vegetation, in the latter examples

\footnotetext{
${ }^{8}$ In this discussion the phytophagous mites and other ecologically comparable arthropods are encompassed along with their more conspicuous insect relatives.
} 
by use of exclosures. Relatively nothing has been done in an attempt to establish insect exclosures (mechanical, chemical, or otherwise) as a means of evaluating the influence of the many highly selective grazers among the insect fauna which abound on those same ranges. There are today many potent, persistent, relatively selective insecticides and acaricides, the possibilities of which should be explored. Much of the evidence presented by Wilson (1943, p. $66 ; 1949)$ is restated here along with other information.

The evidence may be divided into two categories: 1) the examples of significant insect influence on natural vegetation, and 2) the evidence derived from the results of the introduction from other regions of insects (or other biotic agents) for the control of weeds.

Evidence from Studies in Natural Habitats. Albert Koebele in 1902 made one of the first definite studies of the influence of insects on their host plants in their native habitat, with the view to possible introduction of such insects into the Hawaiian Islands for the biological control of the shrub Lantana camara Linn. which had been introduced there as an ornamental but which later became a very serious pest (Perkins and Swezey, 1924). The report of Koebele (1924 [written in 1903]) shows the importance which he placed on the action of various insects on the vigor, distribution and rapidity of spread of this plant in Mexico, and it also emphasizes how much more effective he thought they would be there were they not curtailed by their own effective natural enemies. Many of these insects which were introduced into Hawaii where their natural enemies were absent multiplied very rapidly and did accomplish a high degree of control in certain environments.

Phillips $(1931,1935)$ studied the action of insects on Olinia, Apodytes, Olea, and Ocotea in the Knysna Forests, Cape Province, South Africa. He concluded that insects "probably are wholly necessary for the keeping of a proper balance in the organic scale," but he also stated that he "found no evidence that biotic agents could change the nature of the climax; at most they are responsible, in this region, for originating subseral succession."

In this statement Phillips' extension in his consideration from the action of insects alone to biotic agents in general, and, particularly, his reference to the climax, brings to mind a very significant example of a biotic agent which did change the nature of a climax. The removal of the American chestnut, Castanea dentata Borkh., as a dominant species from the climax deciduous forests of eastern United States through the action of the accidentally introduced fungus, Endothia parasitica (Murr.) And. \& And., was previously cited in another connection. The case of the Bermuda "cedars" was also cited previously in the subsection, "Alien or Native Weeds."

Wilson (1943, p. 66) cited the example of Bews (1920) concerning the influence of certain seed-destroying insects in a climax forest in Natal, South Africa. Bews stated:

"Regeneration in the open spaces of a forest is not always found to be from the seedlings of the dominant surrounding trees. Though these may produce abundance of seed, there are numerous insect pests which, during the stationary climax period, often become so abundant that all the seeds of the dominant species are attacked and none of them are able to germinate. Some of the sub-dominant species may show signs of grad- 
ually supplanting the dominant ones, owing to the influence of such animal agencies, and it is particularly interesting to find that the animal influence can thus prove more potent than the climatic in leading to changes in the climax phase. In other words, the climax type of vegetation may change without any change in climate."

Likewise, Osborn (1924) investigated the influence of insects (and also of plant diseases) on the natural occurrence of pamakani, Eupatorium adenophorum Spreng., in Mexico with the view to introducing such agents into Hawaii and other parts of the world where this plant is a noxious weed. He was one of the first to suggest the role of insects in determining the results of plant competition. He stated “... as I have not seen the plant growing when free from [insect] attack, I may possibly underestimate the effect of a retarded growth in competition with other plants." As a sequel to this work, it is interesting to note that the recent introduction into Oahu and Maui of the tephritid, Procecidochares utilis Stone, by 1950 had resulted in the reclamation of thousands of acres of the more valuable range lands in certain parts of the islands (Bess and Haramoto, in press).

Cook (1942) studied the reasons for the increase of cacti (e.g. Opuntia humifusa Raf.) in the Great Central Basin of Utah. He felt that the moth, Melitara dentata (Grote), and to some degree other insects, in association with climate, had kept the cacti under control for years, but that the drought from 1930 to 1940 had created conditions unfavorable to both the insects and competing plants, and that this conditon opened the field for expansion of the cacti.

On waste lands and palustrine areas of open ranges in California there is an interesting three-way relation involving the shifting fortunes of common dock, Rumex spp., and thus the composition of the vegetation of which it is a part, as involving plant competition and a variation in optimal edaphic conditions for this weed; the injury to the weed by the chrysomelid beetle, Gastrophysa cyanea (Melsh.); and the parasitization of the phytophagous beetle by the parastic wasp, Microctonus gastrophysae (Ash.). A study of this complex was begun several years ago by the author and K. S. Hagen by the use of DDT to isolate the action of the chrysomelid. Some promising evidence was obtained, but the effective action of the phytophagous form was intercepted by the action of the parasitic wasp. Since no material was at that time available which would destroy the wasp without destroying the chrysomelid in a three-way arrangement of comparison plots, the study had to be abandoned.

The work of Chater (1931) on the influence of insects on gorse, Ulex europeus Linn., in its native habitat is of interest. He concluded that because of the very limited seed dispersal, the flower- and seed-destroying forms are of little importance. Also, a small percentage of good seed, viable for many years, would be sufficient. However, he pointed out that the lepidopterous larva, Anarsia spartiella Schr., eats out the growing tips of gorse and ties up the shoots with webbing; and this he considered the most damaging of the insects he observed. He further stated "It was found to be heavily parasitized ... while in the tips of the shoots [after shifting from attack of the flowers earlier in the year] and by 13. vi. 30 only dead or parasitized larvae 
were obtainable." Obviously, in an environment where gorse would be pressed by other efficient and aggressive, competing species, and if the parasites which so successfully attack the phytophagous larvae were not present, this insect might be as effective in the control of gorse as was the thrips, Liothrips urichi Karny, in the control of Clidemia hirta D. Don, when introduced into Fiji (Simmonds, 1933, 1934; Paine, 1934).

Wilson (1943) studied the influence of insects attacking St. Johnswort (also known as Klamath weed and goatweed), Hypericum perforatum Linn., in France. He found that there was great variation in the tolerances of the weed and those of the various insects, such that an insect might cause great damage to it in one area and be of no importance in another. He concluded, however, that "within the limits set by soil, plant succession, and human activity, St. Johnswort is controlled by its insect enemies in southern France."

The work of Tisdale and Zappetini (1953) and of Pringle (1955) indicates a beginning among plant ecologists toward considering the role of insects in studies of range cover. The former authors studied the factors accounting for the recent rapid invasion of Halogeton glomeratus $\mathrm{C}$. A. Mey. on range lands in the western United States. Although they concluded that "prolonged overgrazing appears to have been the major factor responsible for heavy infestations of halogeton" in the native range types, they also recognized that the trends in the shadscale, Atriplex confertifolia Wats., appears to be a result of either overgrazing in the usual sense or destruction of the shadscale by insects. They stated:

"Large denuded portions of the shadscale type contain a major part of the halogeton infestation in the valley. The cause of the wholesale killing of the shadscale itself is not fully understood at present. While some of the dead plants show evidence of previous heavy browsing, many do not. Insect attacks on this species evidently have been severe over the past several years and are still continuing. So far, two insects have been recognized as important in their effect on shadscale. These are a scale insect (Orthezia annae Cockerell) found on the root crown and a hitherto unnamed species of snout moth (Eumysia sp.) which feeds on the foliage."

Pringle (1955) emphasized the role of Trirhabda pilosa Blake. in checking stands of big sagebrush, Artemisia tridentata Nutt. in western United States. It is very likely that the damage occasionally inflicted by this insect would be much more common and more severe were it not in turn attacked by a number of enemies of its own.

Maehler (1948) investigated the near-absence of guavas on Guam because of the importance of this shrub as a reservoir host of the oriental fruit fly, Dacus dorsalis Hendel, which had recently become established in Hawaii and was causing great havoc there. Maehler stated that a small tortricid moth, Spilonota holotrephas Meyrick, was responsible for the scarcity and depauperate condition of the few guavas to be found on the island.

These examples should be sufficient to suggest to what degree insects may be significant for the composition and densities of some plants among our natural or seminatural vegetation, and to what degree the abundance of their specific plant hosts in turn may limit their numbers. Only elaborate qualita- 
tive and quantitative studies can reveal such relations as pertain in each case.

The extreme paucity of statements relating to insects as influents of plant cover in the scholarly work of Clements and Shelford (1939) serves also to emphasize the great neglect of ecologists in this field.

Evidence from Practical Examples of Biological Control. The other aspect of evidence of the possibilities of this method of weed control and the role of biotic agents in plant ecology is derived from practical programs. H. S. Smith, in personal conversation, has stated that he would expect a greater proportion of successes by employment of biological control of weeds than has been experienced in the biological control of insect pests. This is in agreement with actual results up to the present time. Williams (1954) stated, "It is true that the proportion of successes to failures... has been highmuch higher than the proportion in attempts to obtain biological control of insects." However, Williams stated, "Such a comparison, however, is not valid for entomophagous species are often employed against an insect pest when there is no real evidence that natural enemies are at all important to its economy." The present author does not consider this objection, although pertinent, as invalidating the favorable position of biological control of weeds as compared with that of insect pests.

This may be due to the following reasons: (1) Weed subjects have been almost exclusively pests of relatively undisturbed, uncropped range lands, where human interferences are at a minimum. (2) Such weeds are also engaged in a more intense and more direct competition with other claimants of the requisites, many of which may become competitively superior at the site as a result of only slight destruction of the weed by a phytophagous insect, without actual mortality of individuals being occasioned by the insect's feeding. (3) Action of insects introduced to control a weed may occasion additional damage associated with encouragement of fungous, bacterial or other disease organisms (Dodd, 1940; Wilson, 1943). (4) With weeds, in contrast to insect pests, there seems to be no marked, general deterrant to effective control by introduced agents in temperate regions compared with tropical. (5) Attempts made in this field have necessarily been restricted to examples where there are indications of promise, whereas with insect pests, this has not often been so, as Williams (1954) stated. (6) There is also introduced a new factor not at all similar to the situation with insect pests. Plants do not invariably, in fact, usually do not die from the attack of a single insect.

Paradoxical as it may seem, other things being equal (an inconceivable state), and given an insect capable of directly or indirectly destroying its host at some level of its own numbers, those which are required in greater numbers to do the job one would otherwise do are more effective natural enemies, since they would be maintained as more ubiquitously occurring, cohesive, effectively searching populations (e.g., undercrowding phenomena of Allee, et al., 1949) at lower host densities. Hence the hosts could be held at lower levels of abundance (Nicholson, 1933, on entomophagous parasites vs. predators). However, the plant occupies such a different position in the ecosystem from that of a phytophagous insect that the direct comparison implied is of doubtful value. 
The evidence derived from practical examples, wherein introduced insects have brought under control a weed which reached excessive abundance in a new land, does not mean necessarily that the weed's excessive abundance in the new home, as contrasted to its scarceness in its native land, was due solely or mainly to the absence there of the insect or insects which were introduced, or others of equally effective action. In such cases, effective control over the weed in its native home is likely but cannot be assumed in the absence of other evidence. If an insect is introduced to attack a plant and its own entomophagous enemies are excluded, it may have greater effect than in its original home where its own enemies hold it in check. It does mean obviously that the introduction was a success and that in the new environment, it is limiting for the weed, whether or not such was the case in the region native to them.

Examples which may be considered outstanding as evidence are the control of prickly pear, Opuntia stricta Haw. and $O$. inermis DC. in Australia by the phycitid moth, Cactoblastis cactorum (Berg.), introduced from South America (Dodd, 1940) (see fig. 1) ; the control of Koster's curse, Clidemia hirta D. Don in Fiji by the introduction of the thrips, Liothrips urichi Karny, from Trinidad (Simmonds, 1933, 1934); and the recent control of St. Johnswort, Hypericum perforatum Linn., in western United States (Holloway and Huffaker, in preparation) (see fig. 3) by the introduction of the European chrysomelid, Chrysolina gemellata (Rossi). Biologists associated with the work of these introduced insects credit to the pressure exerted by them gross general changes in the vegetative cover. In each case much of the land was seminatural and used mostly for grazing.

The same can be said to a lesser degree concerning several other examples, the results of which have been good but not so striking, or which have not developed sufficiently far to permit adequate evaluation at this time. In this category may be mentioned the programs of biological control of Lantana in Hawaii by the introduction from Mexico of eight species of insects (see Perkins and Swezey, 1924); the control of St. Johnswort, Hypericum perforatum Linn., in Australia and Canada by introduction of Chrysolina spp. and a root-boring buprestid, Agrilus hyperici Creutz, (Wilson, 1943; Parsons, 1954 ; Smith, in press) the control of black sage in Mauritius by the introduction from Trinidad of the galerucid, Schematiza cordiae Barb., and, to a lesser degree the seed-infesting chalcid, Eurytoma sp. nr. howardi D. T. (Williams, 1951); the program in New Zealand for control of ragwort, Senecio jacobaeae Linn., by the ragwort seed-fly, Pegohylemia jacobaeae Hardy ; of gorse, Ulex europaeus Linn., by the seed-weevil, Apion ulicis Forst., and of piri-piri or Acaena by the saw-fly, Antholcus varinervis Spin. (Miller, 1936 ; 1947); the control of pamakani, Eupatorium adenophorum Spreng., on the islands of Oahu and Maui (Hawaiian Islands) by the introduction from Mexico of the tephritid, Procecidochares utilis Stone (Bess and Haramoto, in press); and, among others, the various examples throughout the world of control of prickly pear, Opuntia spp., by the cochineals, Dactylopius opuntiae (Ckll). and D. tomentosus Lam., and by Cactoblastis cactorum (Berg.) (van der Goot, 1940; Pettey, 1948, for example). 


\section{ENVIRONMENTAL FITNESS AND THE CHOICE OF AGENTS}

The following three subsections cover the general features of environmental fitness, but a number of important points relative to the practical aspects of culture and colonization, although relating to environmental fitness, are discussed in the subsection of "Culture and Colonization" of the section on "Procedures."

\section{The Aggressiveness of Weeds in Invaded Regions}

It is well known that when an injurious insect gains entrance into a favorable new country it frequently is far more noxious than in its native home. This is true also of introduced weeds-due in part to the absence or reduction of phytophagous controls, but in some cases also to other factors of increased favorableness. There is no reason to assume that the point of origin of a species necessarily represents its maximum in favorableness ecologically, although this may be so, as Wilson (1949) stated. This is considering such factors as climate, soil, and other plant competitors, even in the absence of natural enemies.

The eminent American ecologist H. A. Gleason spent much of his life proving unsound the Clementsian concept of unquestioned, superior adaptation to climate of the "climax dominants." He emphasized that the dominants are only those which among the existing flora win out in the environment, and that if other species, evolved in an entirely different part of the world, perhaps, were present, the dominants would not necessarily be those same species. Although Gleason did not carry the argument to this point, it might be added that the presence of other animals likewise may affect the situation. From this, it may be concluded that not only the physical environment, but the existing fauna and flora, as well, may act to exclude or to permit various degrees of, even excessive, success of an arrival alien to an environment. This point, applicable to biological control in general, becomes particularly obvious when considering weed subjects.

Therefore, as previously stated, the native home of a plant or an animal by no means necessarily represents the environment inherently most conducive to its abundance.

The physical conditions in some other part of the world may be at least as suitable qualitatively, and far more extensive quantitatively. Our economic concepts of aggressiveness and noxiousness of a weed are based primarily upon the extensiveness of its general replacement of other more desirable plants, not upon how well it may succeed in very limited microareas. Although, as Wilson (1949) stated, “...the physical environment [of the invaded home where an alien weed is very noxious] is unlikely to be more favourable than that of the indigenous area in conjunction with which the plant has evolved," it is believed that this would apply only to the perfection of adaptation to specific physical conditions. The extensiveness of the respective physical conditions which closely conform to the adaptations could just as well be far greater in the invaded region-and hence, the weed would have far greater potentials of abundance, irrespective of natural enemies.

For example, the optimal habitat of a plant (or an insect) in its native 
land may be represented there by a very limited number of very small arenas bordering an oasis, whereas similar habitats far more extensive in area may exist in some other region of the earth where such a form may have been forbidden by distance or barriers from claiming advantage of occupancy. The requirements in edaphic or meteorological conditions could be involved.

The beet leafhopper, Circulifer tenellus (Baker) and one of its summerhost plants, Russian thistle, Salsola kali var. tenuifolia Tausch., are examples. Russian thistle and other acceptable host plants among the Chenopodiaceae are present in the North African region bordering the Sahara Desert, as is the leafhopper. Although host plants of a wide variety of winter annuals of the genera Lepidium, Malcolmia, Plantago, and Erodium are present during the early spring over vast regions there, the severity of the arid summer season is such that these quickly die, and the habitats which retain adequate summer moisture and have suitable edaphic conditions for support of Russian thistle and other suitable summer hosts of this leafhopper are extremely reduced in total area. The leafhopper is therefore limited in North Africa by a severe seasonal restriction in host plants during summer (based on the author's observations). Much more extensive regions with adequate summer moisture and edaphic conditions for support of Russian thistle and other host plants of this leafhopper during summer occur in the Great Basin and Southern California regions of the western United States, such that both the weed and the insect are far more abundant there than in the Sahara region where they are apparently endemic. This statement should not be construed as excluding the possibility that natural enemies significantly contribute to the differences in abundance.

Role of Both Plant Competitors and Animal Influents. The influence of both on the success of a weed in an invaded region, irrespective of the presence or absence of the phytophagous enemies which attack it in its native land, is obvious. The Mediterranean region of Eurasia and North Africa has been a very fertile one for the evolution of plants which are especially adapted to limited amounts of rainfall, and to the utilization of winter rains to a maximum degree during winter and early spring in habitats where soil moisture, in conjunction with severe overgrazing, is too scarce to permit survival of a general perennial grass cover.

In an environment in the United States which conforms to the special adaptations of one of these plants, it is quite possible that such a form would be capable of gaining dominance over native species. Soil moisture during summer over much of semiarid western United States would be adequate, in the absence of excessive grazing, to support a perennial grass cover. Applying Gleason's principle, the dominant perennials would not necessarily be capable of maintaining their position in competition with any of the Mediterranean species which might invade the region, but undisturbed, vigorous, perennial grasslands in a well-balanced status in the biome in which they evolved would be expected to yield very unreadily to such invaders. Excessive grazing or soil disturbance such as has been common in this region may so weaken this complex biotic barrier that such Mediterranean aliens have a bonanza of opportunity there. This is an important reason for the extensive development of Russian thistle in western United States (Piemeisel and Lawson, 1937 ; Piemeisel, 1945). 
Another example of a superior alien is that of St. Johnswort, or Klamath weed, Hypericum perforatum Linn., in California. It had been known to maintain under virtually complete dominance for periods up to twenty-five years, areas which it had taken over and held from the climax bunchgrass, Danthonia californica Boland. Overgrazing was not, in some cases at least, the primary explanation. Removal of this weed by beetles permitted rapid return of Danthonia in one study area (Huffaker, 1951).

The geologic isolation of Australia and the consequent absence of mammals made possible the origin there of varied forms of marsupials which fill the niches that would otherwise be occupied by the more efficient mammals. This is a clear example of a native fauna which is competitively less efficient in utilizing the resources than other forms evolved elsewhere, but which are not present there to claim advantage. It emphasizes the point that a specific environment only offers the challenges to evolution (Dobszhansky, 1950) but that the results of that evolution are not necessarily the most successful competitors which have evolved anywhere for utilization of those particular resources. The original material on which natural selection can act in its further compounding are limiting aspects. The striking successes of the Dingo and the rabbit upon their arrival in Australia as mammalian competitors of their earlier marsupial counterparts is well known (see Huxley, 1953, 1954).

Wholeness of the Environment and Possible Greater Favorability to Introduced Agents. Obviously then, the physical environment, the influence of animals in changing the advantage of plant competitors, or in opening up a habitat, the respective inherent efficiency of the faunal and floral elements in that environment, compared with that of alien elements, as well as the presence or absence of natural enemies which attack a weed directly, may account for its greater or less noxiousness and abundance in an invaded region, compared with the native home.

On the other hand the present paper amply illustrates the common contention that the abundance and aggressiveness of an alien weed may be due to an absence of effective phytophagous enemies in the new home, rather than to increased favorableness of the environment in other respects. The reader is referred to the section on "The Role of Insects in Plant Ecology" for this evidence.

It cannot be overemphasized that the previously mentioned factors may serve to augment the chances of control by the importation of phytophagous insects, compared with that experienced in the native region, just as readily as they may act to increase the inherent potentials of the weed in the new region.

Not only has an introduced phytophagous enemy greater chance of effecting control of the alien weed because of the absence of its own natural enemies in the new region, but the new total environment may be inherently more conducive to the insect than was the original one. Also, as previously stated, the greater the abundance of the weed the greater the chances of finding an insect capable of significantly reducing its abundance, other things being equal. Wilson (1949) stated, "It frequently happens, when an introduced beneficial insect has proved of value in one country, that an attempt is made to establish it in another suffering from the same pest. While this 
practice is often convenient, it may have no sound theoretical basis, and such an insect may have less effect in the second country than would an insect which proved of little or no value in the first." This point can be carried further. An insect which is much less effective than another in its native home may prove much more useful in the control of the weed in the invaded region (see also Cameron, 1935). An example is the case of St. Johnswort in southern France and in California. Wilson (1943) stated that the root borer, Agrilus hyperici Creutz., was the principal insect controlling that weed in southern France. Yet, Holloway and Huffaker (1952) found the leaf beetle, Chrysolina gemellata (Rossi), to be a far more rapid and effective agent of control of this plant in the new home area of northern California. It cannot yet be said whether this will be so at final equilibrium.

\section{The Relation of Climate to the Choice of Agents}

Wilson (1949) presented a pertinent analysis of the relation of climate in the selection of species for introduction. Some of his conclusions are:

" 1 . It is evident that different, but closely related species commonly play precisely the same role in relation to the host [plant] in different areas [where the plant has a wider distribution than any of its phytophagous enemies] and that the essential differences between the species consists in their special adaptations to particular climates.

" 2 . The climates of the regions of distribution of the weed in the invaded and in the native regions should be thoroughly studied as a basis of selection of subjects for introduction.

" 3 . The insect to be selected should be the species most numerous [rather, most effective] in the region climatically most resembling the climate of the invaded region; and conversely, superiority of an insect in an area dissimilar in climate to the invaded region, is no indication that it will prove of value [or that a form inferior to it may not prove of more value].

" 4 . When the phytophagous species becomes so numerous in local areas in the native region as to nearly eliminate the weed, and only one or two species survive in large numbers, these are the important ones. Since it is just such conditions of host plant control with resultant severe insect competition that it is hoped to produce in countries where the weed has been introduced, it seems logical to introduce only those species that become dominant in the homoclime under conditions of local control of the host. This would improve the extreme slowness of such investigations and decrease the risk, if any, in introducing additional, perhaps unnecessary species."

However, the present author would point to what has become almost a maxim in biological control that it is extremely problematical to attempt to predict the outcome, or to select in advance the best species for introduction, if based upon climatic analyses alone, as stated by Dodd (1940, p. 23), although such approaches are to be recommended and should in some cases prove fruitful. If the most promising species prove unsuccessful, other species should then be tried. 
One difficulty is that of deciding just what are the criteria in equating climates. A single, apparently minute difference in two otherwise very similar climates may be the factor of importance. Thus, Holloway and Huffaker (1952) observed and Huffaker and Kennett (1952) experimentally demonstrated that the differences in the specific synchronization in physiological responses of Chrysolina gemellata (Rossi) and C. hyperici Forst. to moisture during the fall of the year, correlated with the particular pattern and intensity of dry and wet seasons as related to their life cycles, account for the successful control of Klamath weed in northern California by C. gemellata and the rather minor effectiveness of $C$. hyperici. In this case, a conclusion based upon an equating of general climates could prove erroneous.

\section{The Pyramid of Adaptations and Exploitation}

The author believes that the more steps removed from the plant furnishing the food, and the greater the exactitude in adaptations and the number of times near-perfect adaptations (synchronizations, for example) are required, the less likely that evolution will have produced a biotic relation wherein the exploiter acts as a dominant regulating agent over the population levels of the exploited. This has great significance for biological control in general, as well as for weeds in particular.

Although there is little direct quantitative experimental evidence supporting it, the concensus seems to be that, other things being equal, more effective regulating action is likely to result from a primary parasitism of a phytophagous host than will result in the case of a parasite which attacks the parasite of the phytophagous species-that is, a secondary will be less likely to control the density of its host. Carrying this in both directions, there is still less likelihood that a strictly tertiary parasite will exert effective control over the secondary; and, in the other direction, there should be greater likelihood that a phytophagous insect will control its plant host than that it will be checked prior to this by its own enemies. However, this last comparison is not necessarily valid, for the plant is an entirely different type of organism, occupying a different position in the ecosystem perhaps more directly dependent upon the physical environment and competition with other plant species. It is also significant that many insects attack plants in ways which do not reduce their abundance or cause their death, and this is not so with entomophagous insects in relation to their hosts.

Smith (1929) presented valid reasons for introducing a complex of species for control of insect pests, with these serving to supplement one another in areas where each might have advantage. The same reasons must apply also in the consideration of weeds. However, the greater risk involved in the introduction of phytophagous species necessitates a cautious approach, and it would seem prudent to follow Wilson's suggestion of introducing the most likely subjects, one or a few at a time, if there are obvious reasons for expecting certain ones to prove more effective.

The control of insects by employment of natural enemies is considered most likely to succeed when the pest species have holodynamic life cycles such as are characteristic in even, tropical or subtropical environments (Smith, unpublished lectures; Clausen, 1952a, 1952b; Doutt, 1955). Clausen stated 
that of the 30 to 40 fully successful examples of biological control of insect pests, the undoubtedly more frequent success in the tropical and subtropical areas can be attributed to the more even, milder climates, compared with temperate regions. Effective control by natural enemies is not so likely to be periodically or sporadically intercepted by adversity.

The heterodynamic forms are those which have evolved adaptations enabling their survival during hazardous periods, and often involving synchronizing devices such as diapause or behavior which results in occurrence of very marked broods with little overlapping. These latter are more characteristic of continental climates, or otherwise rigorous environments. Dobzhansky (1950) stated that in such environments the challenges in evolutionary progress have been due largely to physical stresses, and that fewer and fewer forms characterized by complex biotic relations can have met the challenges where there are several seasonal periods of different hazardous nature alternating. Clausen (1956, pp. 65, 108) has given examples of the way this feature militates against effectiveness of natural enemies.

Hence, a given plant (weed or otherwise) in rigorous environments would be less likely to have had evolved insects which control its abundance. The insects which attack the phytophagous insects would be one more step involved in dependence upon perfect synchronization and adaptation: with the physical environment, with the plant upon which its host feeds, and with its phytophagous host itself. Therefore, there is a reduced chance of effective action by an insect enemy of a phytophagous form in environments rigorous for it, and if the phytophagous form is one which attacks a weed, then its chances of being held in suppression by its own natural enemies are less than would be the case in milder, more even environments, or if it were of the holodynamic type. Consequently, control of the weed by the phytophagous form would be more likely.

The successes in the biological control of weeds seem to have been proportionately more common in rigorous environments than has been the case with biological control of plant-feeding insects in those environments (Williams, 1954 ; H. S. Smith, personal conversations). In the biological control of insects, the rigorous environment with the associated heterodynamic life cycle is considered a definite deterrent, comparing this with the mild environment with the associated holodynamic life cycles. This same principle would probably hold, but to a lesser degree, with respect to biological control of weeds.

\section{PROCEDURES}

There are many general precautions and procedures for use in this work which are similar to those employed in the biological control of insects. These will not be discussed, and the reader is referred to such general works as that of Smith, et al. (1933), Sweetman (1936), Peterson (1937, 1944), Clausen (1940), Flanders, (1940, 1956) and a few of the more elaborately documented specific examples in this field, such as those of Howard and Fiske (1911), Tothill, et al. (1930), Smith and Armitage (1931), Clausen and Berry (1932), Taylor (1937), Clausen, et al. (1936), Haeussler, (1940), Flanders (1930), and Finney, et al. (1947).

The work of Cameron (1935), Sweetman (1936), Dodd (1940), Wilson 
(1943), and Pettey (1948) covers examples of biological control of weeds and contain much information on precautions and procedures.

The steps to be followed in chronological order are foreign exploration (including a prior study of the literature to determine the best countries to explore), biological studies and "starvation testing" of promising subjects in the country of origin, quarantine considerations and additional testing (including also methods of packaging and shipping), culture and colonization of the imported species, and the evaluation of results.

These points will be discussed only as they require special emphasis in the employment of this method for weed control. The necessary precautions associated with deciding upon the proper weed subjects for this work and the nature of the risks involved, these not being procedural but substantive, were discussed in earlier sections on "The Nature of the Infestations and the Place of Biological Control" and "The Risks Involved."

\section{Foreign Exploration for Natural Enemies}

As in all biological control work, the first place to explore, if known, is that portion of the native home of the pest species which most nearly resembles in climate and general physiognomy of its vegetation (Thornthwaite, 1933) the region in the invaded country where control is desired. The search may be broadened to areas where only very close relatives of the pest species (say, in the same genus) occur if that seems expedient, and if it is not required that the species to be imported must be limited in its attack to a single species.

A general survey should first be made throughout the geographic region which offers promise. In addition to making general observations on all insects found attacking the weed (or its close relatives), inquiry and investigation should be conducted into the possibility that those insects attack other plants in the region studied, so as to obtain preliminary information on the degree of restriction in diet. Museum records are of inestimable value in pursuing this phase. Any information so obtained is a valuable guide in limiting the number of subjects to be tested exhaustively, and the work is thereby greatly expedited.

\section{"Starvation Tests" on Specificity}

The methods used to establish the host-plant affinities of prospective subjects are not necessarily limited to starvation tests. Wilson (1949) and Williams (1954) presented pertinent accounts of the points involved: The starvation tests cannot possibly cover every plant which it might be desirable to protect, and there necessarily must be a limit to the number of species tested. Nor is this necessary, for in most countries there is adequate information for excluding a great many species which are known to attack useful plants occurring there. Those not known to attack such plants must nevertheless be tested against representatives of all useful plant groups occurring in the country. Wilson stated that

"... if it is found in starvation tests that an insect will develop upon some useful plant, it is taken, practically automatically, to indicate that liberation is impermissible. But the test does not constitute any proof that the liberated insect would become a pest of any importance. ... for example, Nupserha antennata Gah., an insect enemy of Xanthium at- 
tacks certain composites under test conditions but apparently does not do so in its native India because these hosts are not in the right stages (Mundell, unpublished data). Similarly, the sawfly, Antholcus varinervis Spin., which has been liberated and established in New Zealand against the Rosaceous weed piri-piri, (Acaena spp.,) has habits that reduce the risks to a minimum, for the adults emerge and oviposit in July when no important Rosaceae except strawberry are in leaf, and the adults are unable to oviposit on strawberry because of its protective vestiture. Also, if a half-grown larva manages in a test to complete its development on some economic plant, a decision against liberation would normally be taken irrespective of the fact that the female must oviposit in an appropriate place and the larvae succeed in reaching the halfgrown stage before the result of the test has any bearing on the risks involved."

Wilson considered that if the special requirements for oviposition are not met, then the ability of immature stages to utilize a plant as food in starvation tests should not be sufficient to deny liberation.

Williams reported that

"... the leaf-eating beetle, Schematiza cordiae Barb., was tested in the orthodox manner by starvation tests in both Trinidad and Mauritius before its release in the latter country against Cordia macrostachya (Jacq.) R. \& S. When it was confined in petri dishes, slight feeding upon several unrelated plants occurred, while appreciable feeding occurred upon the weed and its close allies and also, surprisingly, upon cabbage. When confined in cages, the starved insects would never feed upon cabbage. The life-cycle could be completed only upon the weed, and the insect was eventually released."

Williams also pertinently remarked,

"The data obtained has then to be considered in conjunction with the observed behavior in nature, the botanical isolation of the weed, the value of related plants, and any other information that seems to have a bearing upon the advisability of releasing the insect. The greatest weight should, however, rest with the evidence concerning the ability of the insect to develop upon plants other than the weed."

Especial caution would need to be exercised in extensive continental areas of very diversified agriculture and climate, as these would constitute areas of greater potential risk, as was stated by Sweetman (1936, p. 382).

Williams emphasized that the tests should be conducted in the country of origin and again, only with the promising species, in the invaded country. For reasons of safety, it is imperative that the tests in the invaded country be so limited. It is considered that in the invaded country conditions of plant growth, climate, et cetera, may be such that a form which does not attack a given useful plant in its indigenous area may do so under the new conditions. Rigid tests would reveal any interest potentialities. Painter (1951, pp. 90-95) stated, "Each species of insect in relation to its host plant may be affected by soil conditions in respect to one or more of the factors of resistance, i.e. preference, antibiosis, or tolerance"; and again, "... it proved 
impossible to study resistance of certain strains to wheat stem sawfly under cage conditions because resistance is greatly reduced when the amount of light is slightly decreased." Painter also cited examples wherein temperature and various biological effects of edaphic and climatic factors, such as differences in phases of plant growth, may account, to greater or less degrees, for differences in the expression of resistance. It is also of interest that in some cases, one or more of the host plants of a phytophagous species may confer on it "a kind of immunity to parasitization," to quote Smith (1942) (see also Anon., 1944; Landis, 1937; Flanders, 1942).

These examples are enough to reveal that not only the technique (e.g., the types of cages used in the tests) but the physical environment in which the host plants are grown or the tests conducted, may significantly influence final decisions. Obviously, the widest possible latitude should be allowed in making the tests and in interpreting the results.

There are also certain phytophagous insects which are inherently so restricted to a specific host that testing their acceptability of other plants as hosts is unnecessary. Williams (1954) stated, "... as with Eurytoma sp., which was introduced into Mauritius from Trinidad against Cordia macrostachya (Jacq.) R. \& S., no tests for specificity were made with this insect, for it is a seed-infesting species with a life-cycle closely adapted to the structure and maturation changes of the fruits of its host plant." An equally striking example is that of the introduction of the gall-fly, Zeuxidiplosis giardi Kieff., from France into California, for the control of St. Johnswort, Hypericum perforatum Linn. This insect is so intimately dependent upon the specific insect/plant/hormone relation that it does not induce formation of the galls on plants of other genera (Wilson, 1943). The gall wasps of the family Cynipidae are extensively monophagous (Brues, 1946 p. 100).

\section{Quarantine Considerations}

This subject is so broad and has been covered so much more fully by workers in the biological control of insects than will be possible in this paper, that only a few special points are mentioned herein.

The paper by Smith, et al. (1933) is a standard handbook for general quarantine work. Flanders (1956) discussed quarantine facilities and practices in biological control work and Sweetman (1936) covered some points of general interest.

The type of packaging and containers to satisfy quarantine requirements vary greatly with each case. The life history, stages of the insects to be shipped, their requirements as to temperature, moisture, food, etcetera, are also so variable that no generalities concerning these points are attempted. However, from the precautionary viewpoint it should be stated that the containers should be of sturdy, tight construction, either of wood or metal. If of light plywood, it is advisable that they be covered with fine-mesh cloth sewn at all seams. This is to safeguard against escape of insects even if the packages become smashed through mishap in transit.

The requirements for shipping material from a given country and its entry into the country of destination also vary in every shade and kind of complexity. Every person who has engaged in foreign exploration in this 
line of work will appreciate this remark. Details have to be worked out in each individual case.

Clear, duplicate labelling of packages, including any transit or importation permit stickers, should be standard procedure. Utmost speed in transit, accomplished by air transport, is essential, and previous arrangements of flight schedules usually aid greatly. Upon receipt of the material at the place of destination, the opening of packages is done only in properly approved quarantine rooms under strictest care.

The quarantine facilities should be adequate for conducting starvation or host-specificity tests. The rooms would have to be lighted adequately for the culture and maintenance of plants over long periods of testing. Any economic plants which could not be tested in the country of origin must be included, along with any which are to be retested. Ample stocks of test plants must be maintained for the testing in both countries.

The quarantine operator must exercise strict care in screening out and destroying, not only any other phytophagous insects, but any natural enemies of the insects being introduced. The release of introduced insects in the immature stages is normally particularly to be avoided. The reasons for excluding the natural enemies of the insect being introduced are obvious.

\section{Culture and Colonization}

Culture and Release of Natural Enemies. The culture of natural enemies of weeds is one stage less involved than the culture of entomophagous insects. Workers in biological control of insects must maintain conditions favorable to the plant food, to the insect pest (or a suitable substitute insectary species) which feeds on it, and, as well, to the parasite or predator which attacks the phytophagous species.

With many types of natural enemies being introduced, the mass-culture and release in very large numbers is highly desirable or essential. The favorite technique in insectary practice is to employ, for culture purposes, some unnatural plant or host material (Simmonds, 1944; Finney, 1947, 1953 ; Flanders, 1949, 1956). Thus the common potato tuber has become an extremely useful means of avoiding the many griefs and efforts associated with the culture of growing plants. However, in weed work where only hostspecific phytophagous insects can be used, this device is not available. As it arises, each problem of culture must be solved by the researcher, such as has been done in the cases of the successful examples in this field (Dodd, 1940; Simmonds, 1934; Holloway and Huffaker, 1951; Williams, 1951, for example).

In some cases (e.g., Holloway and Huffaker, 1951) where there is only a single generation of the insect each year and where ideal field conditions for multiplication prevail it is pointless to attempt mass-culture of the insects prior to release. In the case of the colonization of the gall-fly, Zeuxidiplosis giardi Kieff., Holloway and Huffaker (1953) used the simple procedure of transferring infested potted plants to field locations. The plants were infested from a greenhouse culture.

Factors Influencing Work. There are a number of factors of great practical importance in the prosecution of work of this kind regarding the culture 
and establishment of the species being introduced. The presence of destructive indigenous natural enemies, synchronization with the general climate and with the growth phases of the host plant, various aspects of undercrowding associated with very low initial populations, the habitats to select, the time and the numbers to liberate, and the catastrophic dispersal of the material from the points of release are questions to be considered. All who have engaged in projects of this type have considered and solved some of these problems, and Wilson (1949) presented a pertinent synopsis.

In a previous section the role of biotic elements in the environment in impeding or preventing the success of alien arrivals was discussed. When a beneficial form is being introduced it is, at the initial times and points of release, particularly subject to such pressures, as well as others, because of its very low numbers, even if the most favorable times and places for making the releases are chosen. Miller (1936) and Currie and Fyfe (1938) reported the failure to establish the cinnabar moth, Tyria jacobaeae Linn., a natural enemy of ragwort, Senecio jacobaeae Linn., in New Zealand and Australia, respectively, because of predaceous and parasitic attack on the colonization material by indigenous species. Wilson (1949) stated that these are usually "chiefly very polyphagous species." He suggested, for this and other reasons, that releases be made in very large numbers, such that the appetites of such enemies in the local areas of releases might be satisfied without depleting the population too severely. Holloway and Huffaker (1952) adopted a general rule of 5,000 adult beetles for each colonization site they used in the St. Johnswort program in California.

The problems involved in getting introduced species synchronized with the phenological conditions of local environments are often very complicated, particularly if the insects are imported from the opposite hemisphere, or in cases where there are particular problems of adjustment with flowering of the host plant. The former condition was involved in each case in the introduction of Chrysolina gemellata (Rossi) and other St. Johnswort insects from Europe into Australia (Currie and Garthside, 1932), from Australia to the United States (Holloway, 1948), and, again, from the United States into Chile. Those insects which have holodynamic and short life cycles are easily adjusted. If they have a diapause condition which can either be broken very quickly, in order to become synchronized six months early, such as was accomplished by Holloway (1948), or else extended an extra six months so as to be synchronized with the next year, the synchronization can readily be accomplished.

In some cases there may be an inherent barrier to proper synchronization of an introduced enemy with its host in the new environment. Several striking examples of this among the entomophagous insects introduced to control insect pests are known. Clausen (1956) cited the example of Hyperecteina aldrichi Mesnil $[=$ Centeter cinerea $]$. In Japan this parasite emerges in proper synchrony with its host, Popillia japonica Newm., but in the eastern United States it emerges several weeks or more in advance and the adults die before the peak of emergence of the adult beetles. Thus it is ineffective here.

Place of Release. The places chosen for release should not all be of the same ecologic type, but a majority should possess the attributes which evi- 
dence indicates most closely to conform to the requirements of the species to be introduced. But just in case the researcher may be wrong in his appraisal of the best sites for release, he should select several rather distinct locations, particularly if the infestation is extended over a wide range of geographic and climatic conditions. These points can be decided upon only by the researcher actually engaged and familiar with the ecology of both the specific weed and the insects being introduced.

For example, many St. Johnswort infestations on cold, north-facing slopes in California may be so retarded in basal-foliage development in winter that leaf-feeding beetles released there at that time would not have sufficient food for reproduction, such as is especially desirable when initial colonizations are being attempted. On the other hand, warm south-facing slopes present lush basal growth and ideal conditions for Chrysolina gemellata (Rossi) at the same time of year. With Chrysolina hyperici Forst., which does not readily respond to winter moisture, and which customarily continues reproductively inactive for two to three months, anyway, at that period (Huffaker and Kennett, 1952), this factor would not be so important.

Time of Release. The time of day, as well as the time of year, may be very important. Thus, Holloway and Huffaker (unpublished notes) found that Chrysolina should be released in the cool of evening, or else on cool, cloudy days. $C$. gemellata and $C$. hyperici readily take to flight if they are released during the hottest time of the day in full sunlight. Extreme hunger of the beetles adds to this possibility. The material released for colonizing may thus disperse so quickly and so widely that most of the individuals would succumb after reaching inhospitable grounds when exhausted in flight. They might also disperse so widely that later encounters for mating would be very few. At best, the researcher would have to search widely for survivors which may succeed elsewhere in order to follow developments.

\section{Evaluation of Results}

The results from introduction of natural enemies to control weeds are often far more spectacular and easier "to prove" than results from similar introductions for control of insect pests.

The removal of a weed from a range is conspicuous and it leaves space available for the claim of other plants on the range. In this case, it is essentially a foregone conclusion that other plants will soon occupy that space and utilize it. If the great majority of the more aggressive plants occurring on the range are desirable plants, then the vacated space will likely be taken by those forms, with a maximal range improvement.

If in event of removal of a weed by biological control, the more weedy species occurring there, or which might later come in, claim the range, many would say that biological control failed because other weeds came in instead. An energetic, forward-looking supplemental approach would be to try various programs of range management, coupled with reseeding, perhaps, in an effort to make the most of reopened opportunities-with the removal of the pernicious weed, which in many cases (for example, St. Johnswort in California) had long stymied research and initiative toward improvement of those ranges. Murphy, et al. (1954) discussed range seeding and the proper 
timing and intensity of grazing as a means of encouraging return of desirable annual and long-lived perennial forage species following the control of St. Johnswort by beetles or other means.

With regard to the possible invasion by new weeds of space vacated by another due to biological control, there can be no assurances. Undoubtedly, a healthy range is subject to invasion by new weeds. However, referring again to the control of St. Johnswort in California, there are no data indicating that such a weedy species as Medusa-head, Elymus caput-medusae Linn., shows a marked predilection for space recently vacated by St. Johnswort, nor that it is incapable of invading St. Johnswort-infested land or land which never at any time has been so infested. There is not necessarily any basic difference in the final plant composition resulting from a control of St. Johnswort accomplished by beetles and that accomplished by chemical or other means. While it is always desirable that a permanent range cover of the highest value be maintained, no one can say that some other perhaps more serious weed may not some day lay claim to the land, whether or not St. Johnswort were controlled by biological means.

On the other hand, the control of an insect pest by biological means would also leave an open niche for occupancy by some other insect pest, but, contrary to the case with weeds, essentially all such claimants would be harmful in nature. However, considering insect pests, it is not so likely that the tendency to compensation would result in rather full utilization of the niche vacated. If other insect pests were to increase as a result of the vacated niche, there is not the same inclination to lay the blame at the door of the successful project as there is in the case of weeds.

In endeavoring to evaluate results in this field, the ecologist must therefore be concerned, just as must the persons establishing the project, with the possibility that some other prospective claimant of the space may be far more difficult to control than the weed subject, as pointed out by Miller (1936). But no one should take a defeatist's attitude and assume per se that an aggressive prospective, alternate weed is worse and certain to claim the space so vacated. There are far too many reasons why it is unlikely to do so or, at least, to the same extensive degree, or, if so, why it may prove easier to control by conventional means, rather than more difficult.

The methods the researcher must use in evaluating a program depend, again, upon the nature of the project.

In this field, the camera and successive photographs taken at the same locations are excellent aids to evaluation. The more spectacular successes can be recorded pictorially and no greater support can be had for the securing of funds and the establishment of additional projects of this kind. This type of evidence has been used in every principal attempt in this field.

On the other hand, less spectacular but more technical information furnishes a needed supplement to the pictorial record. In this, not only is there need to follow the populations of the natural enemies and the weed subject throughout the course of progress of the work, but the composition of the other vegetation on the land must be considered. Adequate sampling methods must be used. Also, where the results appear to be borderline, an insecticidal check-method to remove the insects in small "control" plots can be employed. 
The use of "check-methods" in appraising the value of entomophagous insects in the control of insect pests suggests the use of related techniques in this field (see Ripper, 1956; DeBach, 1946, 1951). Data relative to life histories and synchronization of the natural enemies, the plant, the climate and edaphic conditions are essential to an understanding of the factors which may contribute to success or failure.

Studies are necessary on the nature of injury to the plants, as the agents used may destroy the plants directly, or contribute to their displacement by plants otherwise competitively inferior to them. The influence of the injury upon the root systems and competition for moisture or mineral nutrients are just as important as top-growth destruction and competition for sunlightparticularly if the environment is one where moisture during the dry season is the dominant requisite in short supply. Studies along these lines, relative to St. Johnswort, were conducted by Huffaker and Holloway (1949), Huffaker (1951, 1953), Huffaker and Kennett (1952), N. Clark (1953), L. R. Clark (1953), and Tisdale, et al. (1953).

Many of the reasons why very successful biological control of St. Johnswort has been experienced in western United States, contrasted with the more limited success in Australia, have emerged from these studies. One basic reason is the slight differences in climate and the nature of the infested regions, there being considerably more rain during summer in the regions of infestation in Australia. Also, the extensive infestations where control was unsuccessful there occur in wooded areas. Such infestations are known to be poorly suited to the most effective action of Chrysolina (Holloway and Huffaker, 1952 ; N. Clark, 1953 ; L. R. Clark, 1953; Parsons, 1954). The infestations of any real importance in western United States were in open, fully exposed ranges. Also, there is here a high realization of reproductive capacity by the beetles and very low recuperative ability of the weed (after beetle feeding ceases in early summer) because of the intense and continuous aridity throughout the remainder of the summer. There is a near-perfect complex of circumstances favorable to control, involving the synchronization of $C$. gemellata, its weed host, the patterns of rainfall and temperature, and the sun-exposed openness of infestations.

Lastly, those in charge of the general programs should include in their evaluation studies the influence on plant succession, soil conservation, and watershed and wildlife values, as discussed in an earlier section, if such seem warranted in the particular case.

\section{SUMMARY}

Weeds are today and since the beginning of agriculture have probably been the principal pest of man's crops. Biological control has been used with eminent success against some of the world's most pernicious weeds, but it is a method which must be employed only as a result of thorough appraisals.

The principal agents used in this work have been phytophagous insects, but other organisms are coming under increasing consideration. These agents may destroy existing plants directly or indirectly, in the latter case by either lowering the capacity of a weed to compete with other plants in the arena or by contributing conducively to destruction by secondarily pathogenic or- 
ganisms. They may also curtail the spread and reëstablishment of the weed in new areas or in places where they have been brought under control by other means.

The framework for biological control of weeds and the hesitancy in its use derive from: (1) the conflict in general acceptance of a plant as a weed, coupled with the fact that introduced enemies of weeds recognize no geographic boundaries, and (2) the risks involved as balanced against the probabilities of success.

The conflict in interest may depend upon where the plant occurs and in what ways it may be beneficial as well as harmful. Very complicated, contrary interests may be involved. The more simplified the economy of an infested region the less likely are the chances of disturbing conflicts of interest.

Biological control of weeds carries with it serious potential dangers ; therefore, precautions to avert these dangers are essential. The probability of success should far outweigh the estimated risk. Recent work on the nature of host selection by phytophagous insects may eventually place this phase on a more predictable basis. Meanwhile, extensive testing of host acceptability is the only assurance against excessive risk. A review of the reported cases of insects which have "changed their diet" lends no disturbing element to prospects in this field.

The chance of success must be appraised for each specific case. Undue emphasis has been placed on forms which attack the plants in particular ways. It is highly desirable that the introduced agents, in interaction with competition by other plants, can destroy existing stands. Curtailment of seed production alone in some cases involving perennial weeds is insufficient. Yet, such action could prove highly efficient in the control of annuals. Emphasis has also been placed on use of this method only for introduced weeds, weeds of natural areas, or those of perennial nature. While these are the most promising subjects, there is no reason to exclude other examples from consideration.

The biological control of weeds fundamentally is a discipline in applied ecology, and its success depends upon an appreciation of the framework of both plant and animal ecology and the interrelations of the integrated communities where the weeds occur.

Beyond considering biological control of weeds as such, it is stressed that there is little justification for the negligence of ecologists to appraise the role of insects and other arthropods in the composition and structure of natural vegetation, or their unilateral emphasis of the factors of the environment such as rainfall, exposure, temperature, winds and edaphic conditions, for example, over the competitive or inhibitive complexes which are just as much an inherent part of the interrelated holocoenotic pattern of causes. While plant ecologists have dealt extensively with the influence of rodents and the larger mammalian herbivores, sometimes employing exclosures for the purpose of evaluation, essentially nothing has been done toward evaluation of the roles of the much more highly selective grazers among the insects which abound on those same ranges. They appear to ignore the possibility that such "influents" may not only influence but actually change the whole pattern of 
effects they assign almost exclusively to the meteorlogic or edaphic conditions. The present paper attempts to clarify the relation of insects in the concept of balance in plant communities, and to establish their important role as one of the regulating actions which may be dominant in time or place, relative to the abundance of specific plants, weeds or otherwise.

\section{ACKNOWLEDGMENTS}

The author wishes to express particular gratitude to Professor Emeritus H. S. Smith of this Department and J. K. Holloway of the United States Department of Agriculture (also Specialist in this Department) for their contributions both of encouragement and actual thought. The author's close association with these men and their fundamental views on ecology and biological control during the past eleven years has been such that it was not always possible to unravel the exact origins of certain ideas utilized in this work.

Appreciation is also expressed for similar contributions of Professors C. P. Clausen, R. L. Doutt, Stanley E. Flanders, and the various other members of this Department who have been of service in many ways.

\section{LITERATURE CITED ${ }^{\circ}$}

Allee, W. C., A. E. Emerson, O. Park, T. Park, and K. P. Schmidt

1949. Principles of animal ecology. W. B. Saunders Co., Philadelphia. [877 pp.]

ANDREWARThA, H. C., and L. C. Birch

1954. The distribution and abundance of animals. University of Chicago Press [782 pp.]

ANONYMOUS

1944. Bibliography on insect pest resistance in plants, with a supplement on resistance to nematodes. Imp. Bur. Plant Breeding and Geneties. Cambridge, England. [39 pp.]

*1945. Entomological investigations. 19th Rep. Coun. Sci. Ind. Res. (Australia), 194445, pp. 19-30. (Canberra)

*1946. Entomological investigations. 20th Rep. Coun. Sci. Ind. Res. (Australia), 194546, pp. 18-24. (Canberra)

Armitage, H. M.

1952. Controlling curly top virus in agricultural crops by reducing populations of overwintering beet leafhoppers. Jour. Econ. Ent. 45:432-35.

BARNES, H. F.

*1952. The gall midges of St. John's wort (Hypericun spp.) with descriptions of two new species. Bul. Ent. Res. 42:697-705.

BENTLEY, J. R., and M. W. TALBOT

1948. Annual-plant vegetation of the California foothills as related to range management. Ecology 29:72-79.

Bess, H. A., and F. H. Haramoto

In press. Biological control of pamakani, Eupatorium adenophorum, in Hawaii. Proc. Tenth Inter. Cong. Ent., 1956.

Bews, J. W.

1920. The plant ecology of the coast belt of Natal. Natal Mus. Ann. 4:367-469.

BODENHEIMER, F. S.

1930. Über die Grundlagen einer allgemeinen Epidemiologie der Insektenkalamitäten.

Ztschr. f. Angew. Ent. 16:433-50.

Brues, C. T.

1920. The selection of food-plants by insects, with special reference to lepidopterous larvae. Amer. Nat. 54:313-32.

${ }^{9}$ Items indicated by an asterisk are not cited in the text. 
1946. Insect dietary. Harvard University Press, Cambridge, Mass. [466 pp.]

1952. How insects choose their food plants. In Insects, the Yearbook of Agriculture, 1952, pp. 37-42. (Washington, D.C.)

Callan, E. McC.

*1948. Effect of defoliation on reproduction of Cordia macrostachya. Bul. Ent. Res. 39:213-15.

Calvert, J.

*1932. St. John's wort in Australia. Austral. Council Sci. and Indus. Res. Jour., Feb., 1932. [8 pp.]

Cameron, E.

1935. A study of the natural control of ragwort (Senecio jacobaeae Linn.). Jour. Ecol. $23: 265-322$.

Carter, W.

1935. Studies on biological control of Pseudococcus brevipes (Ckll.) in Jamaica and Central America. Jour. Econ. Ent. 28:1037-41.

Cashmore, A. B., and T. G. CAMpBetul

*1946. The weed problem in Australia: A review. Austral. Council Sci. and Indus. Res. Jour. $19: 16-31$.

Chapman, R. N.

1931. Animal ecology with especial reference to insects. McGraw-Hill Book Co., New Yörk. [464 pp.]

1933. The cause of fluctuations of populations of insects. Hawaii. Ent. Soc. Proc. 8:279-97.

Chater, E. H.

1931. A contribution to the study of the natural control of gorse. Bul. Ent. Res. 22:225-35.

Clark, L. R.

1953. The ecology of Chrysomela gemellata Rossi and C. hyperici Forst. and their effect on St. John's wort in the Bright District, Victoria. Austral. Jour. Zool. $1: 1-69$.

Clark, L. R., and NANCY Clark

*1952. A study of the effect of Chrysomela hyperici Forst. on St. John's wort in the Mannus Valley, N.S.W. Austral. Jour. Agr. Res. 3:29-59.

Clark, Nancy

1953. The biology of St. John's wort (Hypericum perforatum L. var. angustifolium D. C.) in the Ovens Valley, Victoria, with particular reference to entomological control. Austral. Jour. Bot. 1:95-120.

Clausen, C. P.

1940. Entomophagous insects. McGraw Hill Book Co., New York. [688 pp.]

1952a. Biological control of insect pests. California Citrog. 37:182, 204, 106.

1952b. Biological control of insects: California's subtropical climate favors establishment of natural enemies of agricultural pests. California Agr. 6(11):10.

1956. Biological control of insect pests in the continental United States. U. S. Dept. Agr. Tech. Bull. 1139. [151 pp.]

Clausen, C. P., and P. A. Berry

1932. The citrus blackfly in tropical Asia, and the importation of its natural enemies into tropical America. U. S. Dept. Agr. Tech. Bul. 320. [58 pp.]

Clausen, C. P., J. L. King, and C. Teranishi

1936. Insect parasitism and biological control. Amer. Ent. Soc. Ann. 29:201-23.

Clements, F. E., and V. E. Sheilford

1939. Bioecology. John Wiley and Sons, New York. [425 pp.]

Cook, C. W.

1942. Insects and weather as they influence growth of cactus on the Central Great Plains. Ecology 23:209-14.

Currie, G. A.

1932. Ovipositional stimuli of the burr-seed fly, Euaresta aequalis Loew. (Diptera:Trypetidae). Bul. Ent. Res. $23: 191-9$

1940. Some Australian weed problems. Imp. Bur. Pastures and Forage Crops, Herbage Pub. Ser. Bul. 27:113-30. 
Currie, G. A., and S. Garthiside

1932. The possibility of the entomological control of St. John's wort in AustraliaProgress report. Austral. Council Sci. and Indus. Res. Pamp. 29.

Currie, G. A., and R. V. FyFe

1938. The fate of certain European insects introduced into Australia for the control of weeds. Austral. Council Sci. and Indus. Res. Jour. 11:289-301.

*1939. The lantana bug in Australia_-progress report. Austral. Council Sci. and Indus. Res. Jour. 12:259-63.

DEBACH, P.

1946. An insecticidal check method for measuring the efficacy of entomophagous insects. Jour. Econ. Ent. 39:695-97.

1951. A biological check method for evaluating the effectiveness of entomophagous insects. Jour. Econ. Ent. 44:763-66.

Dethier, V. G.

1947. Chemical insect attractants and repellents. P. Blakiston's Son \& Co. [289 pp.]

1954. Evolution of feeding preferences in phytophagous insects. Evolution $8(1): 33-54$.

DoBzhaNsKY, T.

1950. Evolution in the tropics. American Scientist 38:209-21.

DoDD, A. P.

${ }^{*}$ 1927. The biological control of prickly pear in Australia. Austral. Council Sci. and Indus. Res. Bul. 34. [44 pp.]

*1929. The progress of biological control of prickly pear in Australia. Commonwealth Prickly Pear Board, Brisbane. [44 pp.]

* 1936. The control and eradication of prickly pear in Australia. Bul. Ent. Res. 27:503-17.

1940. The biological campaign against prickly pear. Commonwealth Prickly Pear Board, Brisbane. [177 pp.]

1953. Observations on the stem gall-fly of pamekani, Eupatorium glandulosum. Hawaii. Ent. Soc. Proc. 15:41-44.

1954. Biological control of weeds. Weed Control Conference, Roseworthy Agricultural College, Session 5, August, 1954, pp. 121-23.

DouTT, R. L.

1955. Lectures on biological control of insect pests and weeds as part of a course Entomology 129 given at the University of California, Berkeley.

Essig, E. O.

1926. Insects of western North America. The Macmillan Co., New York [1,035 pp.]

1948. Insects in relation to weed control. Jour. Econ. Ent. 41:58-61.

Finney, G. L., S. E. Flanders, and H. S. Smith

1947. Mass culture of Macrocentrus ancylivorus and its host, the potato tuber moth. Hilgardia 17 (13):437-83.

1953. A technique for mass-culture of the six-spotted mite. Jour. Econ. Ent. 46:712-13.

Flanders, S. E.

1930. Mass production of egg parasites of the genus Trichogramma. Hilgardia 4(16): $465-501$.

1940. Environmental resistance to the establishment of parasitic Hymenoptera. Amer. Ent. Soc. Ann. 33:245-53.

1942. Abortive development in parasitic Hymenoptera induced by the food plant of the insect host. Jour. Econ. Ent. 35:834-35.

1949. Culture of entomophagous insects. Canad. Entomologist 81:257-74.

1956. Principles and practices of biological control. [Mimeo., $94 \mathrm{pp}$.]

Fleschner, C. A.

1952. Host-plant resistance as a factor influencing population density of citrus red mites on orchard trees. Jour. Econ. Ent. 45:687-95.

Franz, J.

In press. The effectiveness of predators and food as factors limiting gradations of Adelges (Dreyfusia) piceae (Ratz.) in Europe. Tenth Inter. Cong. Ent., 1956.

Fullaway, D. T.

1921. The fern weevil, Syagrius fulvitarsis Pasc. Hawaii. Forester and Agr. 28:101-14.

1954. Biological control of cactus in Hawaii. Jour. Econ. Ent. 47:696-700. 
FyFe, R. V.

*1937. The lantana bug, Teleonemia lantanae Distant. Austral. Council Sci. and Indus. Res. Jour. 10:181-86.

GOOT, P. VAN DER

1940. De biologische bestrijding van de cactus-plaag in het paloe-dal (Noord-Celebes). Landbouw 16:413-29. (With English summary.)

HAEUSSLER, G. J.

1940. Parasites of the oriental fruit moth in Japan and Chosen and their introduction into the United States. U. S. Dept. Agr. Tech. Bul. 728 [62 pp.]

HAGEN, K. S.

In press. Influence of adult nutrition upon fecundity, fertility, and longevity of three fruit flies (Diptera, Tephritidae). University of California Publications in Entomology.

Hamlin, J. C.

* 1932. An inquiry into the stability and restrictions of feeding habits of certain cactus insects. Amer. Ent. Soc. Ann. 25:89-120.

Harrison, J. W. H.

1927. Experiments on the egg-laying instincts of the sawfly Pontania salicis Christ. and their bearing on the inheritance of acquired characters; with some remarks on a new principle of evolution. Roy. Soc. London Proc., Ser. B., pp. 115-26.

Holloway, J. K.

1948. Biological control of Klamath weed-Progress report. Jour. Econ. Ent. 41:56.

1954. The use of insects for the biological control of weeds. Fourteenth Western Weed Control Conference Proceedings, pp. 59-62.

Holloway, J. K., and C. B. HuFfakeR

1949. Klamath weed beetles. Biological control program now is in the second of three phases. California Agr. 3(2):3, 10.

1951. The role of Chrysolina gemellata in the biological control of Klamath weed. Jour. Econ. Ent. 44:244-47.

1952. Insects to control a weed. In Insects, the Yearbook of Agriculture, 1952, pp. 13540. (Washington, D. C.)

1953. Establishment of a root borer and a gall fly for control of Klamath weed. Jour. Econ. Ent. 46:65-67.

In preparation. The biological control of Klamath weed in California, 1944-1957.

How ARD, L. O., and W. F. Fiske

1911. The importation into the United States of the parasites of the gypsy moth and brown-tailed moth. U. S. Dept. Agr. Bur. Ent. Bul. 91. [108 pp.]

Hoy, J. M.

${ }^{*} 1949$. Control of Manuka by blight [a coccid, Eriococcus sp.]. T. c. No. 4, pp. 321-24.

HUFFAKER, C. B.

1951. The return of native perennial bunchgrass following the removal of Klamath weed (Hypericum perforatum Linn.) by imported beetles. Ecology 32:443-58.

1953. Quantitative studies on the biological control of St. John's wort (Klamath weed) in California. Seventh Pac. Sci. Cong. Proc. 3:12-14. (Royal Soc. New Zealand, Wellington.)

In press $a$. The concept of balance in nature. Proc. Tenth Inter. Cong. Ent., 1956.

In press $b$. Principles of biological control of weeds. Proc. Tenth Inter. Cong. Ent., 1956.

HufFaker, C. B., and J. K. Holloway

1949. Changes in range plant population structure associated with feeding of imported enemies of Klamath weed (Hypericum perforatum Linn.). Ecology $30: 167-75$.

HuFfaker, C. B., and C. E. KenNeTT

1952. Ecological tests on Chrysolina gemellata (Rossi) and C. hyperici Forst. in the biological control of Klamath weed. Jour. Econ. Ent. 45:1,061-64.

1956. Experimental studies on predation: Predation and cyclamen mite populations on strawberries in California. Hilgardia 26(4):191-222.

HuXLEY, J. S.

1953. Evolution in action. Harper and Brothers, New York. [182 pp.]

1954. The evolutionary process. In Evolution as a Process. George Allen and Unwin Ltd., London. [367 pp.] 
Imms, A. D.

1926. The biological control of insect pests and injurious plants in the Hawaiian Islands. Ann. Appl. Biol. 13:402-23.

1929. Remarks on the problem of the biological control of noxious weeds. Trans. Fourth Inter. Cong. Ent., 1928 (Ithaca).

1937. Biological control of noxious weeds. In Recent Advances in Entomology, pp. 410-19. E. Blakiston and Sons, Philadelphia.

JANVIER, $\mathrm{H}$.

*1933. Étude biologique de quelques Hyménoptéres du Chili. Ann. Sci. Nat. Zool. 16: $209-56$.

JePSON, F. P.

* 1930. Present position in regard to control of prickly pear (Opuntia dillenii Haw.) in Ceylon by the introduced cochineal insect, Dactylopius tomentosus Lamk. Trop. Agr. (Ceylon) 75:63-72.

Jolivet, PikrRe

1954. Phytophagie et Selection Trophique. Volume Jubilaire, Victor Van Straelen. L'Institut Royal Des Sciences Naturelles De Belgique. Tome II.

KoEbele, A.

1924. The introduction into Hawaii of insects that attack lantana. Hawaii. Sugar Planters' Assoc. Expt. Sta., Ent. Ser. Bul. 16. [83 pp.]

KRAUSS, N. L. H.

*1953. Notes on insects associated with lantana in Cuba. Hawaii. Ent. Soc. Proc. 15: 123-25.

LANDIS, B. J.

1937. Insect hosts and nymphal development of Podisus maculiventris (Say) and Perillus bioculatus (F.) (Hemiptera, Pentatomidae). Ohio Jour. Sci. 37:252-59.

LEVER, R. J. A. W.

*1945. Annual Report of Entomologist for 1944. Fiji Dept. Agr., Agr. Jour. 16:87-88. [Work on Clidemia and Lantana.]

MAEHLER, K. L.

1948. The oriental fruit fly in Guam. Jour. Econ. Ent. 41:991-92.

Martin, J. H., and S. C. SAlmoN

1953. The rusts of wheat, oats, barley, rye. In Plant Diseases, The Yearbook of Agriculture, 1953. Pp. 329-43 (Wash., D.C.)

MiLleR, D.

* 1929. Control of ragwort-Experimental work with the cinnabar moth. New Zealand Jour. Sci. and Technol. 11:112-19.

1936. Biological control of noxious weeds. New Zealand Jour. Sci. and Technol. 18: 581-84.

*1940. Biological control of noxious weeds of New Zealand. Imp. Bur. Past. Forage Crops, Herb. Publ. Ser. Bul. 27:153-57.

1947. Control of gorse by seed weevil. New Zealand Jour. Agr. 75:341-44.

Miller, D., A. F. Clark, and L. J. Dumbleton

*1936. Biological control of noxious insects and weeds in New Zealand. Cawthron Inst. Sci. Res. Pub. No. 16.

MUIR, F.

1914. Presidential address. Hawaii. Ent. Soc. Proc. 3:28-42.

MurPhy, A. H., R. M. Love, and L. J. BerRy

1954. Improving Klamath weed ranges. California Agr. Expt. Sta. Ext. Ser. Cir. 437. [16 pp.]

NiBLETT, $M$.

*1955. Some insect inhabitants of the knapweeds (Centaurea spp.) London Nat. 34: 7-10.

Nicholson, A. J.

1933. The balance of animal populations. Jour. Anim. Ecol. Supplement to Vol. 2, No. 1:132-78.

1954. An outline of the dynamies of animal populations. Austral. Jour. Zool. 2:9-65. OsBoRN, H. T.

1924. A preliminary study of the pamakani plant (Eupatorium glandulosum H.B.K.) 
in Mexico with reference to its control in Hawaii. Hawaii. Planters Rec. 28: $546-59$.

PaINe, R. W.

1934. The control of Koster's curse (Clidemia hirta) on Tareuni. Fiji Dept. Agr., Agr. Jour. 7:10-21.

PAINTER, R. H.

1951. Insect resistance in crop plants. The Macmillan Co., New York. [520 pp.]

Parsons, W. T.

1954. A review of the control of St. John's wort in Victoria. Weed Control Conference, Roseworthy Agricultural College, Session 5, August, 1954, pp. 121-23.

Pepper, J. H.

1955. The ecological approach to management of insect populations. Jour. Econ. Ent. $48: 451-56$.

Perkins, R. C. L., and O. H. Swezey

1924. The introduction into Hawaii of insects that attack lantana. Hawaii. Sugar Planters' Assoc. Expt. Sta. Ent. Ser. Bul. 16. [83 pp.]

Peterson, A.

1937. A manual of entomological equipment and methods. Part II. Alvah Peterson, Columbus, Ohio. [334 pp.]

1944. A manual of entomological equipment and methods. Part I. Alvah Peterson, Columbus, Ohio. [21 pp. +150 pages of plates and tabular data.]

Peitey, F. W.

*1946. Biological control of prickly pear. Farming in So. Africa, Reprint No. 6, January. $[3 \mathrm{pp}$.

1948. The biological control of prickly pears in South Africa. So. Africa Dept. Agr. Sci. Bul. 271. (Pretoria) [163 pp.]

\section{Phillips, J.}

1931. The biotic community. Jour. Ecol. 19:1-24.

1935. Succession, development, the climax, and the complex organism: an analysis of concepts. Jour. Ecol. 23:210-46.

Piemeisel, R. L.

1945. Natural replacement of weed hosts of the beet leafhopper as affected by rodents. U. S. Dept. Agr. Cir. 739. [48 pp.]

Piemeisea, R. L., and E. Carsner

1951. Replacement control and biological control. Science 113:14-15.

Pismeisel, R. L., and F. R. Lawson

1937. Types of vegetation in the San Joaquin Valley of California and their relation to the beet leafhopper. U. S. Dept. Agr. Tech. Bul. 557. [28 pp.]

Pringle, W. L.

1955. A new look at sagebrush control. Unpublished paper presented at the annual meeting of the Pacific Northwest Section, Amer. Soc. Range Mgt., Yakima,

QuAYLe, H. J. Washington (U.S.A.).

1926. The codling moth on walnuts. California Agr. Expt. Sta. Bul. 402. [33 pp.]

RIPPER, W. E.

1956. Effect of pesticides on balance of arthropod populations. Ann. Rev. Ent. 1:403-38.

Robbins, W. W., A. S. CRAFts, and R. N. RAynor

1942. Weed control-A textbook and manual. MeGraw-Hill Book Co. [543 pp.]

RoDriguez, J. G., and L. D. RODRIGUEz

1952. The relation between minerals, B-complex vitamins and mite populations in tomato foliage. Ent. Soc. Amer. Ann. 45:331-38.

SCHROEDER, C.

1903. (Cited from: E. L. Boisvier. 1922. The Psychic Life of Insects. Pp. 143-4. The Century Co., New York.)

SEWELL, T. G.

*1949. Manuka blight survey. New Zealand Jour. Agr. 79:101-04. (Wellington).

Simmonds, H. W.

*1928. The introduction of Teleonemia lantanae into Fiji. Fiji Dept. Agr. Jour. 1:17-19.

*1930. The introduction of Liothrips urichi into Fiji. Fiji Dept. Agr. Jour. 3:55-66. 
1933. The biological control of the weed Clidemia hirta D. Don., in Fiji. Bul. Ent. Res. $24: 345-48$. (London.)

1934. Biological control of noxious weeds, with special reference to the plants Clidemia hirta (The Curse) and Stachytarpheta jamaicensis (Blue Rat Tail). Fiji Dept. Agr. Jour. 7:3-10.

Simmonds, F. J.

1944. The propagation of insect parasites on unnatural hosts. Bul. Ent. Res. 35:219-26.

* 1948. The effective control by parasites of Schematiza cordiae Barber, in Trinidad. Bul. Ent. Res. $39: 217-20$.

*1949. Insects attacking Cordia macrostachya (Jacq.) Roem. \& Schult. in the W. Indies. I. Physonota alutacea Boh. (Coleoptera, Cassididae). Canad. Ent. 81:185-99.

Sмiтh, H. S.

1929. Multiple parasitism: Its relation to the biological control of insect pests. Bul. Ent. Res. $20: 141-49$.

1935. The role of biotic factors in the determination of population densities. Jour. Econ. Ent. 28:873-98.

1941. Racial segregation in insect populations and its significance in applied entomology. Jour. Econ. Ent. 34:1-13.

1942. A race of Comperiella bifasciata successfully parasitizes California red scale. Jour. Econ. Ent. 35:809-12.

1947. Biological control of weeds in the United States. Washington Ent. Soc. Proc. $49: 169-70$.

Undated. Lectures on biological control of insect pests and weeds, as part of a course Entomology 129 given at the University of California, Berkeley.

Smith, H. S., and H. M. Armitage

1931. The biological control of mealybugs attacking eitrus. California Agr. Expt. Sta. Bul. $509: 1-74$.

Smith, H. S., E. O. Essig, H. S. Fawcett, G. M. Peterson, H. J. Quayle, R. E. Smith, and H. R. TOLLEY

1933. The efficacy and economic effects of plant quarantines in California. California Agr. Expt. Sta. Bul. 553. [276 pp.]

Smith, J. M.

In press. Biological control of Klamath weed in British Columbia. Tenth Inter. Cong. Ent., 1956.

Solomon, M. E.

1949. The natural control of animal populations. Jour. Anim. Ecol. 18:1-35.

SWEETMAN, H. L.

1936. The biological control of insects (with a chapter on weed control). Comstock Publ. Co., Ithaca, N.Y. [461 pp.]

TAYLOR, T. H. C.

1937. The biological control of an insect in Fiji. Imp. Inst. Ent., London. [239 pp.]

Thompson, W. R.

1929. On natural control. Parasitology 21:269-81.

1939. Biological control and the theories of the interactions of populations. Parasitology $31: 299-388$.

1951. The specificity of host relations in predaceous insects. Canad. Ent. 83:262-69.

ThornthwaIte, C. W.

1933. The climates of the earth. Geog. Rev. 23:433-40.

THORPE, W. H.

1939. Further studies on pre-imaginal olfactory conditioning in insects. Roy. Soc. London Proc., Ser. B. 127:424-33.

Thorsteinson, A. J.

1953. The role of host selection in the ecology of phytophagous insects. Canad. Ent. $85: 276-82$.

In press. Physiology of host plant selection by insects. Tenth Inter. Cong. Ent., 1956. TILDEN, J. W.

*1951. The insect associates of Baccharis pilularis De Candolle. Microentomology 16: 149-85. 
Tillyard, R. J.

*1927. Biological control of St. John's wort. New Zealand Jour. Agr. 35:42-45.

1929a. The biological control of noxious weeds. Trans. Fourth Inter. Cong. Ent., 1928, 2:4-9. (Ithaca.)

1929b. The biological control of noxious weeds. Roy. Soc. Tasmania Proc. 1929, pp. $51-86$.

TINBERGEN, N.

1953. Social behavior in animals. John Wiley, New York. [150 pp.]

Tisdale, E. W., W. L. Pringle, and M. Hironaka

1953. St. Johnswort on Idaho range lands. A preliminary report. Idaho Univ. Forest, Wildlife and Range Expt. Sta. Res. Note No. 6, May (Mimeo.)

Tisdale, E. W., and G. ZAPPETINI

1953. Halogeton studies on Idaho ranges. Jour. Range Management 6:225-36.

Tothill, J. D., T. H. C. TAYlor, and R. W. Paine

1930. The coconut moth in Fiji. A history of its control by means of parasites. Imperial Bur. Ent., Queen's Gate, S. W. 7, London. [269 pp.]

Uvarov, B. P.

1931. Insects and climate. London Ent. Soc. Trans. 79:1-247.

WHYTE, R. O. (editor)

* 1940. The control of weeds. A symposium on the prevention and eradication of weeds on agricultural land by cultural, chemical, and biological means. Imperial Bur. Pastures and Forage Crops, Herb. Pub. Ser. Bul. 27. (Aberystwyth, Gt. Br.) [168 pp.]

Williams, F. X.

${ }^{*} 1922$. Notes on some enemies of the nut grass in the Philippines. Hawaii. Planters Rec. 26:95-97.

Williams, J. R.

*1950. The introduction of Physonota alutacea Boheman (Col., Cassid.) into Mauritius. Bul. Ent. Res. 40:479-80.

1951. The control of black sage in Mauritius by Schematiza cordiae Barb. (Col., Galerucid). Bul. Ent. Res. $42: 455-63$.

1954. The biological control of weeds. Report of the Sixth Commonwealth Ent. Con.,

WiLson, F. London, July, pp. 95-98.

1943. The entomological control of St. John's wort (Hypericum perforatum L.) with special reference to the weed in southern France. Austral. Council Sci. and Indus. Res. Bul. 169. [ 87 pp.]

1949. The entomological control of weeds. International Union Bio. Sci., Ser. B., No. 5, pp. 53-64.

1950. Biological control of weeds. In New Biology. Penguin Books No. 8, pp. 51-74.

1953. Some aspects of the control of weeds by insects. Proc. Seventh Pac. Sci. Cong., Royal Soc. New Zealand, Wellington, Vol. 3, pp. 294-99.

1954. Some aspects of the biological control of weeds in Australia. Weed Control Conference, Roseworthy Agricultural College, Session 5, Aug., 1954, pp. 105-13.

YAMADA, T. and K. WATANABE

*1952. Studies on the sterility in Sudan Grass. I. Sterility caused by the insect, Calocoris rubrovittatus Matsumura. Bul. Nat'l Inst. Agr. Sci. (Yahaga, Japan) Ser. G. 4:209-16. (In Japanese with English Summary.) 

The journal Hilgardia is published at irregular intervals, in volumes of about 600 pages. The number of issues per volume varies.

Subscriptions are not sold. The periodical is sent as published only to libraries, or to institutions in foreign countries having publications to offer in exchange.

You may obtain a single copy of any issue free, as long as the supply lasts; please request by volume and issue number from:

Agricultural Publications

Room 22, Giannini Hall

University of California

Berkeley 4, California

The limit to nonresidents of California is 10 separate issues on a single order. A list of the issues still available will be sent on request. 


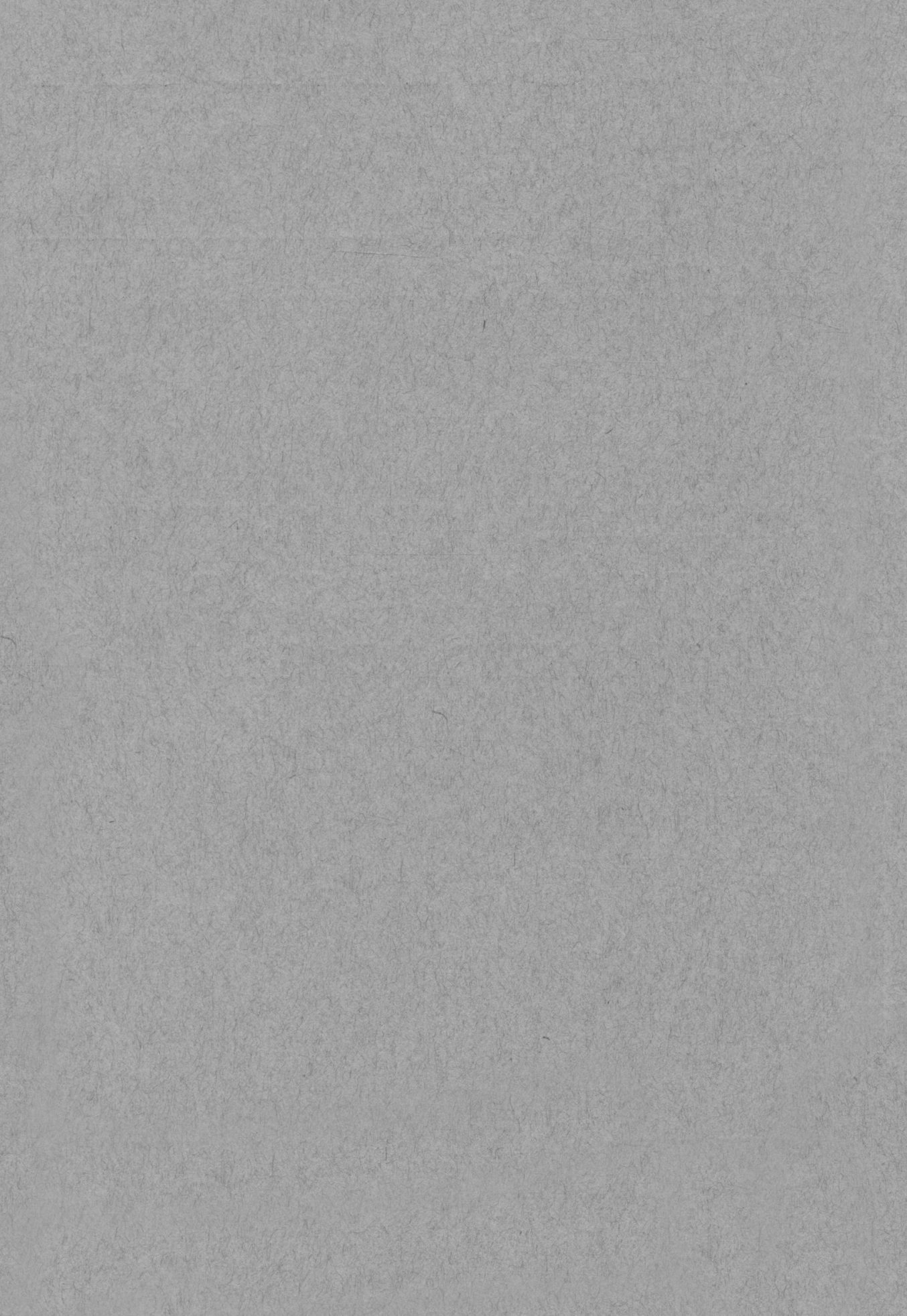

